\title{
Mathematical Modelling of Mooring Systems for Wave Energy Converters-A Review
}

\author{
Josh Davidson * and John V. Ringwood \\ Centre for Ocean Energy Research, Maynooth University, Maynooth, Co. Kildare, Ireland; \\ john.ringwood@nuim.ie \\ * Correspondence: josh.davidson@nuim.ie
}

Academic Editor: Jens Peter Kofoed

Received: 1 February 2017; Accepted: 3 May 2017; Published: 11 May 2017

\begin{abstract}
Mathematical analysis is an essential tool for the successful development and operation of wave energy converters (WECs). Mathematical models of moorings systems are therefore a requisite in the overall techno-economic design and operation of floating WECs. Mooring models (MMs) can be applied to a range of areas, such as WEC simulation, performance evaluation and optimisation, control design and implementation, extreme load calculation, mooring line fatigue life evaluation, mooring design, and array layout optimisation. The mathematical modelling of mooring systems is a venture from physics to numerics, and as such, there are a broad range of details to consider when applying MMs to WEC analysis. A large body of work exists on MMs, developed within other related ocean engineering fields, due to the common requirement of mooring floating bodies, such as vessels and offshore oil and gas platforms. This paper reviews the mathematical modelling of the mooring systems for WECs, detailing the relevant material developed in other offshore industries and presenting the published usage of MMs for WEC analysis.
\end{abstract}

Keywords: wave energy; mooring; mathematical modelling

\section{Introduction}

Mathematical modelling is crucial for the design, analysis and optimisation of WECs. An essential development trajectory to an economically competitive WEC requires early device experimentation and refinement using numerical tools [1]. Significant effort has been undertaken to develop and implement models describing the hydrodynamic interaction between the fluid and the WEC [2]. An accurate wave-to-wire model for a WEC must also include the dynamics of the WEC power take-off (PTO) system [3]. Equally, for classes of floating WECs, a suitable mathematical model of the WEC mooring system is required.

For floating WECs, a mooring system is required to keep the device on station. A mooring system is any type of cable, chain, rope, or tether that connects a WEC to an anchoring system fixed on the sea floor. Mooring costs represent a significant portion of total costs for a WEC installation [4], and are therefore a driver of WEC economic competitive ability. Additionally, the mooring system influences the dynamic behaviour of the WEC, contributing nonlinear resistance and reactance to the WEC dynamics and, unlike free-floating structures, moored floating bodies experience enhanced coupling between various modes of motion. MMs are therefore important for the design, analysis and optimisation of the overall WEC performance, as well as the mooring system itself.

Mathematical analysis is particularly important for mooring systems because physical modelling of the moorings is problematic. As an example, during both tank testing and prototype trials for the Wave Dragon device reported by Friis-Madsen et al. [5], the relatively shallow waters did not allow a proper catenary system to be tested. In the full scale tests performed by Vickers and Johanning [6] in real sea conditions, the lack of controllability of the open sea experiments led to anomalies being observed 
that could not necessarily be quantified. One major obstacle in physical testing of mooring systems is due to the dynamic response of mooring lines being scale-dependent, whereby perfect dynamic similitude between full-scale prototypes and small-scale physical models is difficult to achieve [7]. Difficulties with scaling effects in physical modelling of mooring systems, plus their inherent costs, therefore increase the relevance/importance of MMs for the analysis of full scale systems [8-11].

However, despite their importance, a relatively limited amount of analysis on mathematical modelling for WEC mooring systems is available in the literature. A review of WEC mooring systems is given by Harris et al. [4], but a review of mathematical modelling methods for these systems does not exist. A few reviews of MMs from general offshore engineering fields, were performed at the end of the 20th century. The major contributions came from: Brown et al. [12], who performed a comparative study on numerical calculation of mooring line dynamic loading by 15 different mooring solvers. Thomas [13] details a comparison of the predictions of mooring line dynamics using different time integration schemes, indicating which scheme is to be preferred, highlighting the numerical problems which can be expected to affect the quality of the solution, and how best to avoid these numerical problems. Chatjigeorgiou and Mavrakos [14] comparatively examine two different numerical schemes dealing with mooring dynamics.

However, mooring systems for WECs entail a number of key differences from general offshore applications, as outlined in Section 2.2. A limited amount of analysis has been performed for the specific case of mooring systems for WECs. For example, the various dynamic analysis options available for WEC mooring system design are discussed by Thomsen et al. [15]. A method and application for validating numerical models for WEC mooring systems is presented in Harnois et al. [16]. Yang et al. [17] compare four simulation procedures for the analysis of fatigue of WEC moorings, while Bhinder et al. [18] compared the modelling of three different mooring nonlinear effects using three different software packages. Vissio et al. [19] compare two different mooring models for use in their numerical simulations of the "ISWEC" WEC device, and state that "...One of the main challenges with this system is finding a suitable mooring line model, in terms of accuracy and the corresponding computational expense of the simulation".

The objective of this paper is provide a review and analysis of mathematical modelling for WEC mooring systems to fill this gap. To fufil this objective, the paper aims to identify the different mathematical modelling methods for WEC mooring systems, review their usage in the literature relating to WEC analysis and discuss the strengths and weaknesses of the different modelling methods for the different required applications in WEC analysis. The paper is organised as follows:

- Section 2 provides an overview of mooring systems in wave energy conversion, detailing the different types of mooring systems, the requirements of WEC mooring systems and a comparison with moorings in other offshore engineering fields.

- Section 3 outlines the mathematical modelling of mooring systems, identifying the variables and parameters in the mooring system and the physical effects that the models aim to describe.

- Section 4 then details the different model types used to analyse mooring systems, such as static, quasi-static and dynamic models. The different methods available to numerically implement the dynamic models are presented, looking at the different spatial and temporal discretisation options, linearisation and frequency domain techniques, and system identification of simpler parametric models. The type of coupling between the mooring and WEC models is then discussed.

- Section 5 features the different software packages available for performing mathematical modelling of mooring systems, listing the different commercial, open-source and in-house software packages used within the literature reviewed in this paper.

- Section 6 outlines the types applications that MMs are used for in WEC analysis. For each application a literature review is collated, providing examples of when MMs were utilized for the different applications, the type of WEC and mooring system investigated, and what type of model was employed.

- $\quad$ Section 7 presents a discussion, and then conclusions are drawn in Section 8. 


\section{Mooring Systems in Wave Energy Conversion}

Just as there is diversity among the different types of WEC devices, there is similar diversity among the associated mooring systems and their requirements. An overview of different generic types of WECs and discussion of their mooring requirements is provided by [4]. Other good overviews of WEC mooring systems include Johanning et al. [20,21] and Fitzgerald and Bergdahl [22].

The relevance of a mooring system for a particular type of WEC depends on the operating principle of the WEC. Obviously, for nonfloating WECs, a mooring system is completely irrelevant. However, for floating WECs, the relevance of the mooring system may range from minimal where the mooring is only required for station-keeping, to highly relevant where the mooring is an integral part of the WEC's PTO system. For some classes of directional floating WECs, such as terminator or attenuator devices, the mooring system must allow the WEC to weathervane into the predominant wave direction, while for axisymmetric point absorber type WECs the wave directionality is not important. Mooring systems have been classified into three categories, depending on their relevance to the WEC operation [15,23-25]; passive, active and reactive:

- Passive mooring: when the only purpose of the mooring is station keeping and it does not influence the power extraction of the WEC from the waves.

- Active mooring: when, in addition to providing station-keeping, the mooring system also has a significant influence on the dynamic response and power extraction of the WEC.

- Reactive mooring: when the mooring system provides reaction forces for the WEC to extract power from the waves. In this case, the mooring is an integral part of the system, perhaps linking the floating part of a WEC to the PTO, and are therefore especially suited when the PTO exploits the relative movements between the WEC and the sea floor.

\subsection{Requirements}

A good mooring system must maintain the position of the WEC under extreme loading conditions and ensure its survivability, while also allowing efficient conversion of wave energy in operational conditions [24]. In general, the requirements for WEC mooring systems can be summarised [22,26,27] as follows :

- Accommodate tides.

- All components must have adequate strength, fatigue life and durability for the operational lifetime. Corrosion must be considered and controlled in the design, and abrasion due to bottom contact or contact with other lines must be minimised or avoided if possible.

- Assure device self-orientation with incoming wave direction, if required.

- Be easy to monitor and maintain.

- Be economical.

- Ensure device survivability.

- Minimize environmental impacts on the seabed or native flora and fauna.

- Not adversely affect the performance of the WEC device by interfering with the device motion used for energy capture.

- Occupy as little space as possible on the seabed, in order to allow the devices to be installed close to each other in arrays.

- $\quad$ Reduce/remove loads on the electrical cables and connections.

- Restrain device excursion within its reserved area.

\subsection{Comparison with Moorings in Other Offshore Engineering Fields}

While there exist many similarities between moorings in wave energy and in other offshore engineering fields, such as shipping and offshore oil and gas, WEC mooring systems pose their own unique set of challenges. Karimirad et al. [25] detail the applicability of different offshore mooring and foundation technologies for WECs. A comparison of station-keeping design for WECs compared 
to offshore oil and gas platforms is performed by Paredes et al. [28], which concludes that a deeper analysis of mooring systems for WECs is required, compared to what is demanded for offshore oil and gas platforms, in order to properly assess the effect on the PTO, and survivability. Likewise, Vickers [29] states that directly implementing the experience of the offshore oil and gas industry could be seen as an appropriate first step; however, due to the added complexity of the operation of WEC devices, the design approach for WEC moorings needs deeper consideration.

Design standards of WEC moorings compared to other offshore fields given by Johanning et al. [20], who discusses how existing standards used in the offshore oil and gas industry might be adapted, and raises pertinent issues related to the station-keeping of WECs. Johanning et al. [20] suggest that mooring design for WECs must consider new requirements, other than those that are captured in existing offshore standards such as DNV-OS-E301 [30], a view also shared by $[22,31,32]$.

The key differences between WEC mooring systems compared to those from other offshore applications are outlined below:

- Mooring systems for WECs differ from typical offshore structures, since the WEC is typically designed to resonate, rather than to avoid resonance [33]. The objective is often to maximize the motion and induce resonant responses at the dominant wave frequency (WF). Therefore, WEC mooring systems need to be designed with regard to dynamics in the WF range [34], whereas, in other offshore industries, the "static" design principles require that the mooring system's resonance is far from any exciting frequencies, and the ideal system has no motion response to waves or wave groups [10].

- WECs are usually installed in relatively shallow water depths, compared to other floating offshore structures, where the tidal range is large compared to the water depth and may be more difficult to accommodate. Additionally, the tidal flow can be significant at these nearshore locations. Due to the relatively small size of WECs, and their being moored in relatively shallow waters, the effect of waves, tide and current can be of greater significance than for other floating offshore systems $[10,35]$.

- WECs absorb large quantities of energy from the waves, which affects the characteristics of the drift forces [34]. As an example, while the horizontal drift forces will, in general, have the direction of the wave propagation, Hong et al. [36] show that the Backward-Bent Duct Buoy (BBDB) WEC has horizontal mean drift forces opposite to the wave direction. Similarly, Retzler [37] presents the results of an experimental investigation of the slow drift motions induced by second order wave drift forces on the Pelamis WEC. The drift forces were found to be mostly due to wave power absorption, and Retzler [37] concludes that, because of the absorbed wave power, the Pelamis is subjected to considerably larger drift forces than a vessel of similar dimensions.

- To maximise their economic viability, it is likely that WECs will need to be deployed in densely packed arrays, as developers attempt to exploit the maximum amount of energy for a given sea surface area. This will also help to reduce the length of expensive power cables connecting devices. The seabed footprint area and the allowable excursion of each device within the array will therefore be restricted. The challenge this presents to the mooring system is unique $[6,11,22]$. Anchor sharing between multiple mooring lines in a WEC array, will cause cyclic loading on the anchor to alternate in many different directions, which is not well understood in offshore geotechnics, since typical floating offshore oil and gas platform facilities only have one mooring line connected to one anchor [38].

- WECs will have power cables/umbilicals connected which may affect the device dynamics [39-41]. Although this is in general different to other offshore applications, the case of floating production, storage and offloading (FPSO) units for offshore oil and gas have risers, which have comparable effects and can be modelled using similar methods.

- Finally, there is typically a difference in economics between wave energy conversion and other offshore industries. For example, the revenue generated by a WEC is orders of magnitude lower than that of an oil platform [22]. 
Although this section has shown a number of differences between mooring systems for WECs and other offshore fields, many of the mathematical modelling techniques developed to analyse mooring systems in the offshore engineering fields are useful for wave energy applications, as discussed in Section 3.

\subsection{Mooring Components and Configurations}

Figure 1 depicts that a mooring system consists of different components and materials, arranged in a certain configuration. A good review of the different mooring system types and classifications is given by Harnois [35], and the different components and configurations are reviewed by Karimirad et al. [25]. The report in [26] establishes an industry knowledge base for existing anchoring and mooring techniques as applied to WECs and provides practical guidance on anchors and mooring techniques and sources of reliable design information necessary to the design of WECs. The report contains information on anchors, mooring lines and connecting hardware, and mooring configurations.

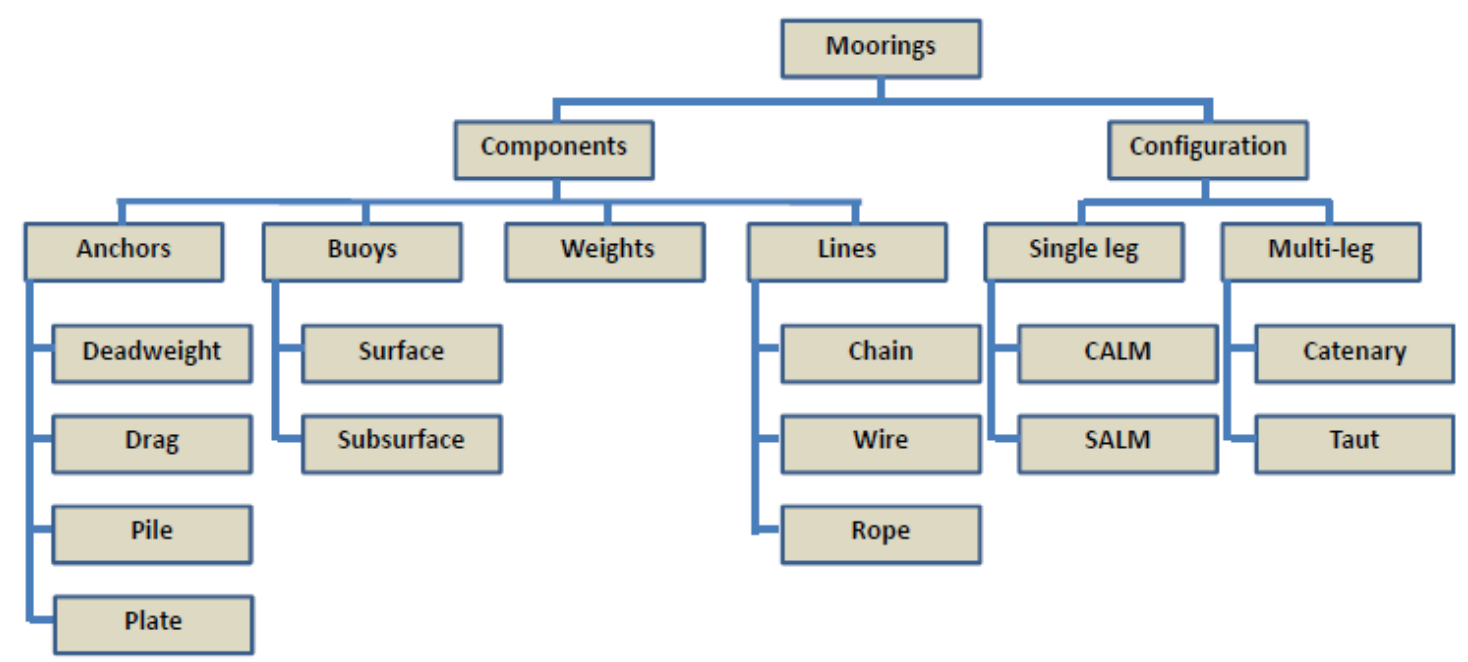

Figure 1. Depiction of the elements which combine to make a mooring system (adapted from [26]).

\subsubsection{Components and Materials}

A mooring system is comprised of mooring lines, anchors and connectors. Additionally, buoys and clump weights can be attached to the mooring lines. Different materials can be chosen for a mooring line: for example chains, fibre ropes or wire ropes. A comparison of different mooring line materials is given by Harnois [35]. The choice of material will influence factors such as the inertia, elastic stiffness and damping of the mooring line. The role of an anchor is to keep a mooring line attached to a fixed point on the seabed. The main requirements for an anchor are to be able to resist high, horizontal and in some cases vertical, loads in a given seabed type (soft to hard), to be easy to install, and to be cost-effective [35]. Different anchor designs are available, such as: dead weight, drag embedment anchor, pile anchor and plate anchor. Discussions on anchors for WEC systems are given in [26,42].

\subsubsection{Configurations}

Various types of mooring configurations are used for general floating structures, as depicted in Figure 2. The different configurations are classified as a single point, Figure $2 \mathrm{a}, \mathrm{c}$, or spread mooring, Figure $2 b, d$, according to whether there is one or multiple lines connected to the WEC, respectively. Single point mooring allows the WEC to weathervane around the connection point; however, unlike a spread mooring, this arrangement has no redundancy, should a line fail.

Mooring configurations are also classified as taut, Figure 2a,b, or slack/catenary, Figure 2c,d, depending on whether the line is stretched tight under pretension, or hangs loose, respectively. 
A catenary line relies on the weight of chain links or clump weights to provide a horizontal restoring force to the WEC. A taut-line system is composed of wire or synthetic ropes and is normally highly pre-tensioned. As a result, taut-line systems are usually quite stiff, both in horizontal and vertical directions, and can significantly reduce vertical motions of the WEC, if connected to the sea bottom directly [24]. Compared to a catenary configuration, a taut mooring system usually occupies a smaller footprint area on the seabed and the excursion of the floating structure is reduced.

If the influence of the mooring system on the vertical motion of the WEC needs to be minimised, then the top part of mooring lines, directly connected to the WEC, should remain as horizontal as possible. In such cases, buoys can be attached, as shown in Figure 2e,f, where the buoy is attached to the sea bottom by a vertical line and connected to the WEC horizontally. If the compliance of the mooring system needs to be increased, then subsurface buoys and clump weights can be attached to the mooring line, as shown in the lazy-S configuration in Figure 2g, to increase the geometric compliance of the mooring system (see Section 3.5.4).

A study into the consideration of mooring cables configurations for WECs is given in Fitzgerald and Bergdahl [22]. Thomsen et al. [43] consider and compare mooring configurations for large floating, motion-independent WECs, based on traditions from other offshore fields. Harris et al. [4] analyse conventional mooring systems in terms of suitability for wave energy application, describing and assessing different types of mooring configurations. The configurations rated by Harris et al. [4] as highly suitable for wave energy applications are listed below.

- $\quad$ Spread moorings: Catenary mooring, mutli-catenary mooring, and taut spread mooring.

- Single point moorings: Catenary anchor leg mooring (CALM), and single anchor leg mooring (SALM).

(a)

(b)

(c)

(d)

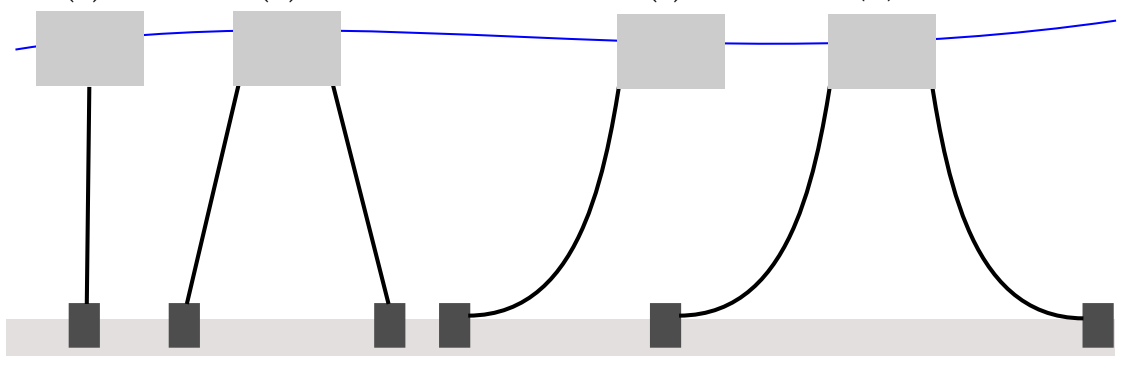

(e)

(f)

(g)

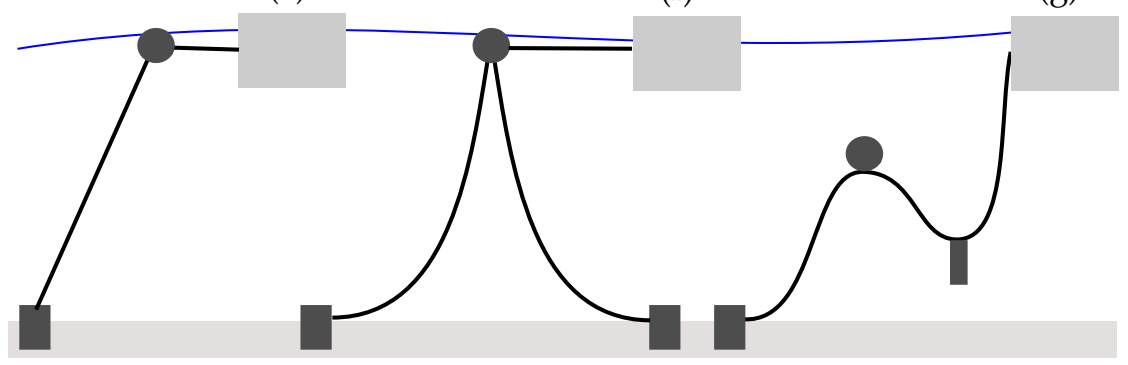

Figure 2. Mooring line configurations: (a) Taut; (b) Taut spread; (c) Catenary (d) Multi-catenary; (e) SALM; (f) CALM; and (g) Lazy-S. 


\section{Mathematical Modelling of Mooring Systems}

Mathematical models for mooring systems have been developed for over 50 years, following the early work of Walton and Polachek [44], Polachek et al. [45], and Harleman and Shapiro [46] in the 1960s. Generally speaking, MMs must be able to predict the hydrostatic equilibrium position and the response due to environmentally induced loadings of the moored system [11]. The MM represents the relationship between the mooring system parameters, variables and environmental inputs. This section identifies the different parameters, variables and environmental inputs relevant to a WEC mooring system. Then, the important physical effects, forces, loads, etc acting on the mooring system are presented, and the mathematical relationships describing these effects detailed.

\subsection{Co-Ordinate Systems}

In modelling a WEC mooring system, there are three main coordinate frames of references to consider, as depicted in Figure 3:

- The global frame of reference $(x, y, z)$,

- The WEC frame of reference $\left(x_{w}, y_{w}, z_{w}\right)$, and

- The curvilinear distance along the mooring line, $s$.

The global frame of reference and the WEC frame of reference are three dimensional, defining the two horizontal and one vertical cartesian co-ordinate. The origin for the WEC frame of reference, $O_{w}$, is defined at the centre of mass of the WEC, and for the global frame of reference the origin, $\mathrm{O}$, is defined at any convenient fixed location. The curvilinear distance is a one dimensional co-ordinate, measured along the mooring line, where $s=0$ corresponds to the bottom end of the mooring line connected to the anchor, and $s=L$ to the top end connected to the WEC ( $L$ is the length of the mooring line).

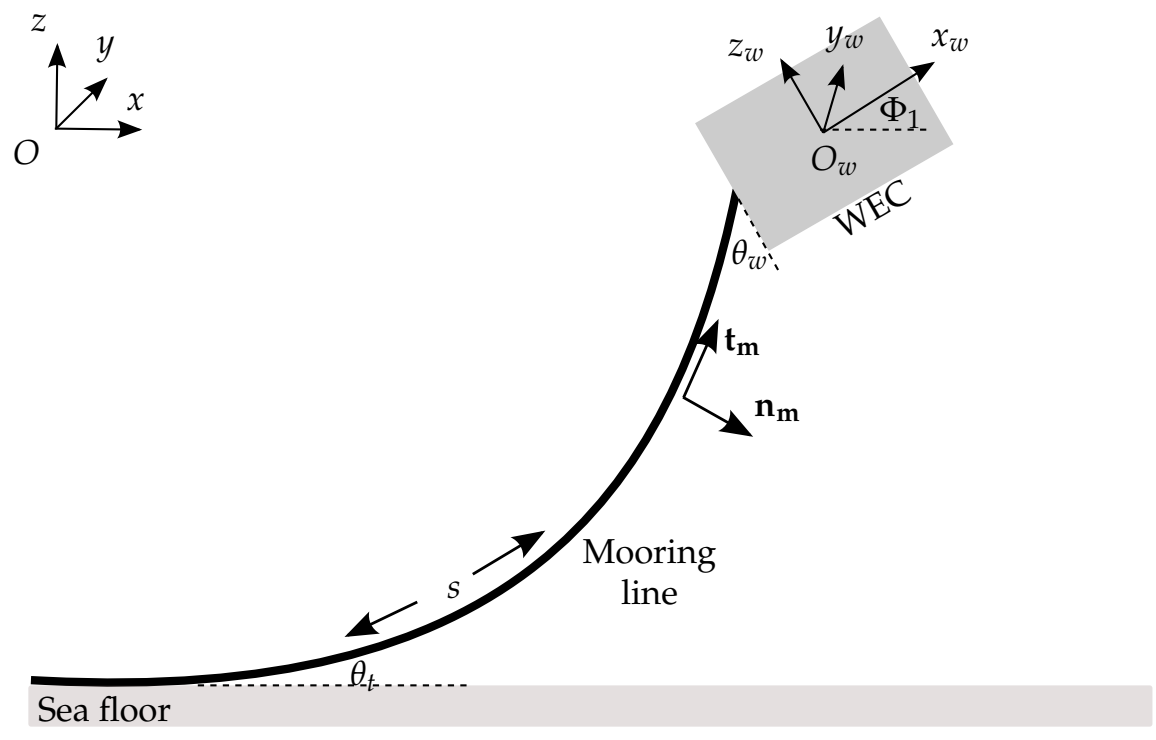

Figure 3. Co-ordinate frames used in the mooring models.

Additionally, the following vectors and angles are useful to define, as depicted in Figure 3:

- $\mathbf{t}_{m}$ : is the unit vector tangential to the mooring line,

- $\mathbf{n}_{m}$ : is the unit vector normal to the mooring line,

- $\theta_{w}$ : is the angle of the mooring line top end with the WEC at the connection point, and

- $\theta_{t}$ : is the angle of the mooring line with the ground at the touchdown point on the sea floor.

- $\boldsymbol{\Phi}$ : is a vector containing three angles: 
- $\Phi_{1}$ corresponds to the angle between $x$ and $x_{w}$ due to the WEC pitch displacement.

- $\Phi_{2}$ corresponds to the angle between $y$ and $y_{w}$ due to the WEC roll displacement.

- $\Phi_{3}$ corresponds to the angle between $z$ and $z_{w}$, due to the WEC yaw displacement.

\subsection{Mooring System Parameters}

There are a number of parameters that define the mooring system and whose values must be selected when designing the system. These parameters are listed in Table 1. A number of the parameters relate to the topology of the mooring line geometry, as depicted in Figure 4, such as the number of mooring lines, the position of the anchor(s) on the sea floor, the location along the line(s) where any buoys or weights are connected, the initial length of the mooring line(s), the location of the connection point(s) on the WEC body where the mooring line(s) are attached, and the diameter of the mooring line(s). The other parameters relate to the material properties of the mooring line, such as its mass density, elasticity, pre-tension and internal damping co-efficient.

Table 1. Mooring system parameters.

\begin{tabular}{lll}
\hline Parameter & Symbol & Units \\
\hline Number of mooring lines & $N_{m}$ & - \\
Initial length of mooring line & $L_{0}$ & $\mathrm{~m}$ \\
Pre-tension of mooring line & $T_{0}$ & $\mathrm{~N}$ \\
Diameter of mooring line & $D$ & $\mathrm{~m}$ \\
Mass density of mooring line & $\rho_{m}$ & $\mathrm{~kg} \cdot \mathrm{m}^{-3}$ \\
Weight of mooring line & $W_{m}$ & $\mathrm{~N}$ \\
Young's modulus / elasticity of mooring line & $E$ & $\mathrm{~N} \cdot \mathrm{m}^{-2}$ \\
Internal damping coefficient of mooring line & $b_{I}$ & $\mathrm{~N} \cdot \mathrm{s} \cdot \mathrm{m}^{-1}$ \\
Connection point on the WEC & $\mathbf{r}_{w}$ & $\left(x_{w}, y_{w}, z_{w}\right)$ \\
Anchor point & $\mathbf{r}_{a}$ & $(x, y, z)$ \\
Buoy connection points along mooring line & $s_{b}$ & $\mathrm{~m}$ \\
Clump weight connection points along mooring line & $s_{c}$ & $\mathrm{~m}$ \\
\hline
\end{tabular}

Top end connection point

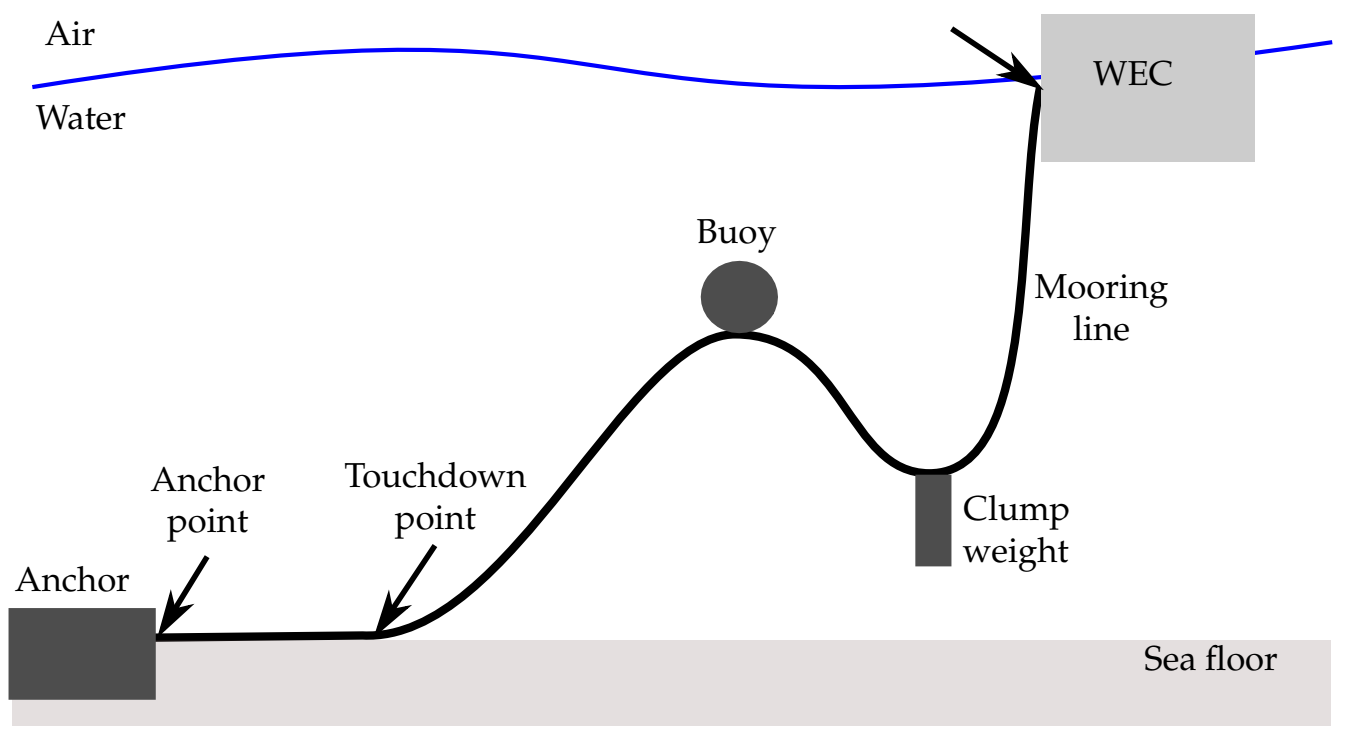

Figure 4. Geometry of the mooring line. 


\subsection{Mooring System Variables}

The mooring system variables are listed in Table 2 and are explained, in greater detail, in the following subsections.

Table 2. Mooring system variables.

\begin{tabular}{lll}
\hline Parameter & Symbol & Units \\
\hline Length of mooring line & $L$ & $(\mathrm{~m})$ \\
Strain of mooring line & $\epsilon$ & - \\
Tension in mooring line & $T(s)$ & $\mathrm{N}$ \\
Position vector & $\mathbf{r}(s)$ & $(x, y, z)$ \\
Touchdown point of mooring line & $\mathbf{r}_{t}$ & $(x, y, z)$ \\
Suspended length of mooring line & $L_{s}$ & $\mathrm{~m}$ \\
Velocity of mooring line & $\mathbf{v}(s)$ & $\mathrm{m} \cdot \mathrm{s}^{-1}$ \\
Acceleration of mooring line & $\mathbf{a}(s)$ & $\mathrm{m} \cdot \mathrm{s}^{-2}$ \\
Position of the WEC & $\mathbf{r}_{W E C}$ & $(x, y, z)$ \\
\hline
\end{tabular}

\subsubsection{Length and Strain}

Due to elasticity, the length of the mooring line can stretch in response to tensile forces arising from the motion of the WEC. The length of the mooring line can be defined as:

$$
L=\int_{\text {Anchor }}^{W E C} d s
$$

The strain of the mooring line, $\epsilon$, is the amount it has been stretched and is defined as the ratio of the instantaneous length, $L$, to the original length, $L_{0}$ :

$$
\epsilon=\frac{L-L_{0}}{L_{0}}
$$

\subsubsection{Tension}

The mooring line tension is typically the value of most interest calculated by a MM. The tension defines the force that the mooring lines impose on the WEC. Additionally, the tension values indicate the maximum and cyclic loads that the mooring lines are subjected to, and are therefore vital in mooring design and in extreme load and fatigue analysis.

The tension is related to the mooring line strain or deformation, $\epsilon$, via a constitutive tension-strain relation with the general form [47]:

$$
T=f(\epsilon, \dot{\epsilon}, s)
$$

where the overdot represents the derivative with respect to time. For the case of a linear stress-strain relationship:

$$
T=E A \epsilon,
$$

where $A$ and $E$ are the the cross-sectional area and Young's modulus of the mooring line.

The tension is a vector, $T$, pointing in the direction of the tangent to the mooring line, $\mathbf{t}_{\mathrm{m}}$. The tension can be decomposed into its horizontal, $T_{H}$, and vertical, $T_{V}$, components. The tension at the top end connection point to the WEC is therefore decomposed into its horizontal and vertical components, $T_{H w}$ and $T_{V w}$, respectively, to determine the effects of the mooring forces on the WEC motion:

$$
\begin{aligned}
& T_{H w}=|\mathbf{T}| \cos \theta_{w}, \\
& T_{V w}=|\mathbf{T}| \sin \theta_{w} .
\end{aligned}
$$


For a taut mooring system, the tension is constant throughout the line. For a slack mooring system, the horizontal tension is constant throughout the line, whereas the vertical tension varies proportional to the effective weight per meter of the mooring line in water, $W$, and the distance along the mooring line from the touchdown point:

$$
T_{V}(s)=W\left(s-\left(L-L_{s}\right)\right)
$$

The tension at any point along a slack mooring line can therefore be given by:

$$
T(s)=\sqrt{T_{H}^{2}+T_{V}(s)^{2}}
$$

\subsubsection{Position}

The position of the mooring line in the global reference frame, $\mathbf{r}(s)$, is largely determined by the positions of its two end points, the anchor and the connection point on the WEC. The position of the top end of the mooring line, $\mathbf{r}(L)$, is determined by the position of the WEC's centre of mass, $\mathbf{r}_{W E C}$, and the mooring line connection point on the WEC, $\mathbf{r}_{w}$ :

$$
\mathbf{r}(L)=\mathbf{r}_{W E C}+\mathbf{r}_{w} \cos \boldsymbol{\Phi} .
$$

For a taut mooring system, the profile of the mooring line is a straight line between the two end points. For a slack mooring line, the profile of a mooring line under static equilibrium, is reasonably well described by the catenary equations:

$$
\begin{gathered}
x(s)=\frac{T_{H}}{W}\left(\sinh ^{-1}\left(\frac{T_{V}(0)+W s}{T_{H}}\right)-\sinh ^{-1}\left(\frac{T_{V}(0)}{T_{H}}\right)\right)+\frac{T_{H} s}{E A} \\
z(s)=\frac{T_{H}}{W}\left(\sqrt{1+\left(\frac{T_{V}(0)+W s}{T_{H}}\right)^{2}}-\sqrt{1+\left(\frac{T_{V}(0)}{T_{H}}\right)^{2}}\right)+\frac{1}{E A}\left(T_{V}(0) s+\frac{W s^{2}}{2}\right)
\end{gathered}
$$

For a slack mooring line, the touchdown point is where the mooring line comes into contact with the sea floor and is locally horizontal. When the WEC drifts away from the anchor, the mooring line will become taut and the touchdown point will move towards the anchor as more line is lifted from the sea floor. Conversely, when the WEC drifts towards the anchor, the touchdown point will move away from the anchor, as more line is laid down on the sea floor. Because the touchdown point depends on the geometry of the sea floor, the local bathymetry may also be considered a parameter of the mooring system. The catenary equations for a mooring line with sea floor contact are described in Garza Rios et al. [48] and Jonkman and Buhl [49]. If the WEC is able to drift sufficiently close to the anchor, the mooring line might become fully slack, running vertically from the WEC to the sea floor, in which case the catenary curve is replaced by an "L" shape and the catenary equations cannot be used anymore.

\subsubsection{Velocity and Acceleration}

The velocity and acceleration of the mooring line are also important variables. Often, it is useful to decompose these variables into the components normal and tangential to the mooring line: $\mathbf{v}_{n}(s), \mathbf{v}_{t}(s), \mathbf{a}_{n}(s), \mathbf{a}_{t}(s)$, where the subscripts $t$ and $n$ represent the tangential and normal components, respectively. 


\subsection{Environmental Inputs}

The environmental inputs which drive the mooring line dynamics are the waves, currents, wind and the variation in water depth due to the tide, as depicted in Figure 5. External forces are directly applied to the mooring lines from the fluid, due to the action of the waves and currents. Additionally, the WEC applies a force to the end of the mooring line, due to the WEC motion, which itself is driven by the waves, currents, winds and the tidal varying water depth.

The exciting forces are a combination of three excitation modes, as described in [50]:

1. Steady current, mean wind and mean wave drift forces are creating a mean force, or static loading;

2. Low Frequency (LF) forces, on the general range of $0-0.02 \mathrm{~Hz}$, are induced by slowly varying wave drift forces, unsteady wind forces, and slowly varying tidal forces;

3. WF forces, on the general range of $0.03-0.3 \mathrm{~Hz}$, are induced by first order wave forces.

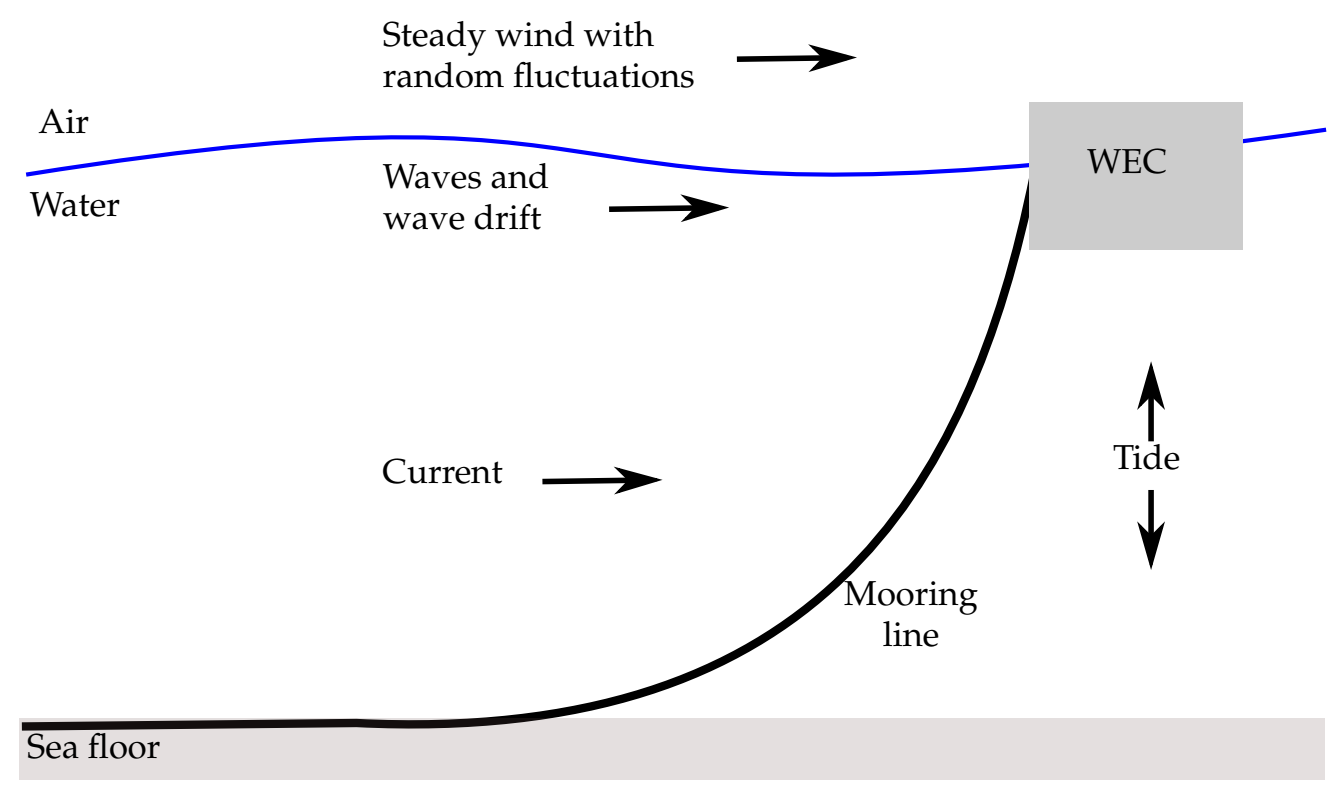

Figure 5. Environmental inputs (adapted from [51]).

Depending on the type of analysis performed, some or all of these inputs can be considered for the MM. For example, recommendations on design inputs for offshore position mooring systems are given in the offshore standard, DNV OS-E301, by Det Norske Veritas (DNV) [30], and for the specific case of WEC mooring systems by Bergdahl [32].

\subsection{Physical Effects}

This section details the different physical effects, present in the mooring system, that the MM must represent. These effects include: the coupling to the WEC, the buoyancy and weight of the cable and attached buoys and clump weights, the interaction with the sea floor, snap loads, and the mechanical impedance of the cable. The mechanical impedance of the cable includes the resistive forces due to damping and the reactive forces due to the inertia and compliance of the cable.

\subsubsection{Connection to the WEC}

The motion of the mooring line connection point on the WEC, due to the WEC motion, defines the boundary condition for the motion of the upper end of the mooring line. While the WEC motion is driven by environmental forces, it is also restrained by forces from the mooring line at the connection point(s). Therefore, the WEC and mooring systems form a coupled system requiring a coupled 
analysis. However, as shown in Section 4.3.4, uncoupled analysis can also be performed to reduce the computational demands, but it gives approximate answers.

\subsubsection{PTO Force}

Certain types of WECs react their wave-induced motion against the sea floor or submerged damper plates. The PTO reaction force is transmitted across the spanning distance, between the WEC body and the sea floor/damper plate, by a taut mooring cable. The PTO force is therefore applied to the WEC via the tension in the mooring line at the connection point. Examples of analysis of these types of systems include [52-55]

\subsubsection{Buoyancy and Weight}

The net buoyancy force, $F_{B}$ equals the difference between the weight of the mooring line acting vertically downwards and the hydrodstatic bouyancy force acting upwards:

$$
F_{B}=\frac{g \pi D^{2} L}{4}\left(\rho_{w}-\rho_{m}\right),
$$

where $g$ is the gravitational constant $\left(9.81 \mathrm{~m} \cdot \mathrm{s}^{-2}\right), D$ is mooring line diameter, $\rho_{w}$ is the mass density of the water and $\rho_{m}$ the mass density of the mooring line. The effective weight per metre of the mooring line in water, introduced in Section 3.3.2, can therefore be expressed as:

$$
W=F_{B} / L
$$

Buoys and clump weights can be attached along the line, which will add positive or negative buoyancy to the attachment points. The introduction of hydrostatic stiffness, in the form of surface buoys or submerged buoys, can reduce the overall cable weight, reduce induced loads and reduce the influence of the cable on the motion response of the device, as shown by Fitzgerald and Bergdahl [22]. The beneficial effects of buoys in reducing the mooring line dynamic tension is shown by Mavrakos et al. [56], provided that proper selection of the buoy size, number and location is performed. Mavrakos and Chatjigeorgiou [57] and Yuan et al. [58] also study the effects and the numerical analysis of attached buoys and clump weights on mooring lines.

\subsubsection{Compliance}

The motion of the WEC must be accommodated by compliance or flexibility in the mooring system. Compliance is typically achieved elastically by stretching of the mooring lines, or geometrically, whereby any curvature or slack in the mooring lines is straightened. Taut mooring lines therefore provide most of their compliance elastically, for which dynamic tension is dominant, whereas slack moorings are able to provide large amounts of geometrical compliance through the straightening of the catenary curve, for which static tension is dominant. When the WEC moves from its equilibrium position, the elastic stretching and/or geometric deformation of the mooring lines will result in a restoring force applied to the WEC from the mooring lines.

Elastic stretching of the mooring lines results in tensions opposing the direction of motion, increasing in a way dependent of the line material stiffness [35]. For small line extensions, the increasing tension can be represented by the linear stress/strain relation in Equation (4). However, certain types of mooring lines may display a nonlinear stress-strain relationship, with material nonlinearity arising from a tension-dependent Young's modulus of the mooring fibre, as is the case of the polyester mooring lines analysed by Tahar and Kim [59]. The stretching of fibre mooring lines is investigated in [60] which concludes that nonlinear springs would better represent the characteristics of some fibre ropes. Therefore, Equation (4) can be modified to include a nonlinear relationship between the elastic stretching of the mooring line and the restoring force on the WEC. For example, the software package ANSYS AQWA [61] uses a fifth order polynomial to model nonlinear mooring line stiffness. 
Alternatively, Tsukrov et al. [62] present a method whereby the elastic modulus is updated at each time step, dependent on the current value of strain in the mooring line.

Slack moorings mainly produce static restoring forces, resulting from the weight of the line. The restoring force can be calculated from the catenary equations, by taking the derivative of the tension with respect to the displacement. Jain [63] presents a simplified method of calculating the equivalent stiffnesses of the mooring cables, derived analytically, by using the basic catenary equation for the cable equilibrium. When the WEC displacement increases, tensions in the mooring lines opposing the direction of motion increase nonlinearly, until the mooring line is fully lifted form the sea floor and becomes taut [11]. Accessory buoys or clump weights can be used to locally modify the weight or buoyancy of the mooring line and consequently the stiffness characteristics of the mooring system [35]. The advantage of using an accessory buoy as a hydrostatic spring is shown by Fitzgerald and Bergdahl [22].

Additionally, slack mooring lines may also present dynamic restoring forces in the case of high frequency (HF) WEC motion, whereby small displacements at the top end of the mooring line, can result in large lateral displacements at the midpoint of the mooring line, as depicted in Figure 6. As the frequency increases, nonlinear drag (which increases with the square of frequency) provides very large lateral resistance, causing the mooring line to 'freeze' in place and the WEC motion to be then accommodated elastically by the mooring line [64]. The thesis by Gobat [65] focuses on the dynamics of geometrically compliant moorings.

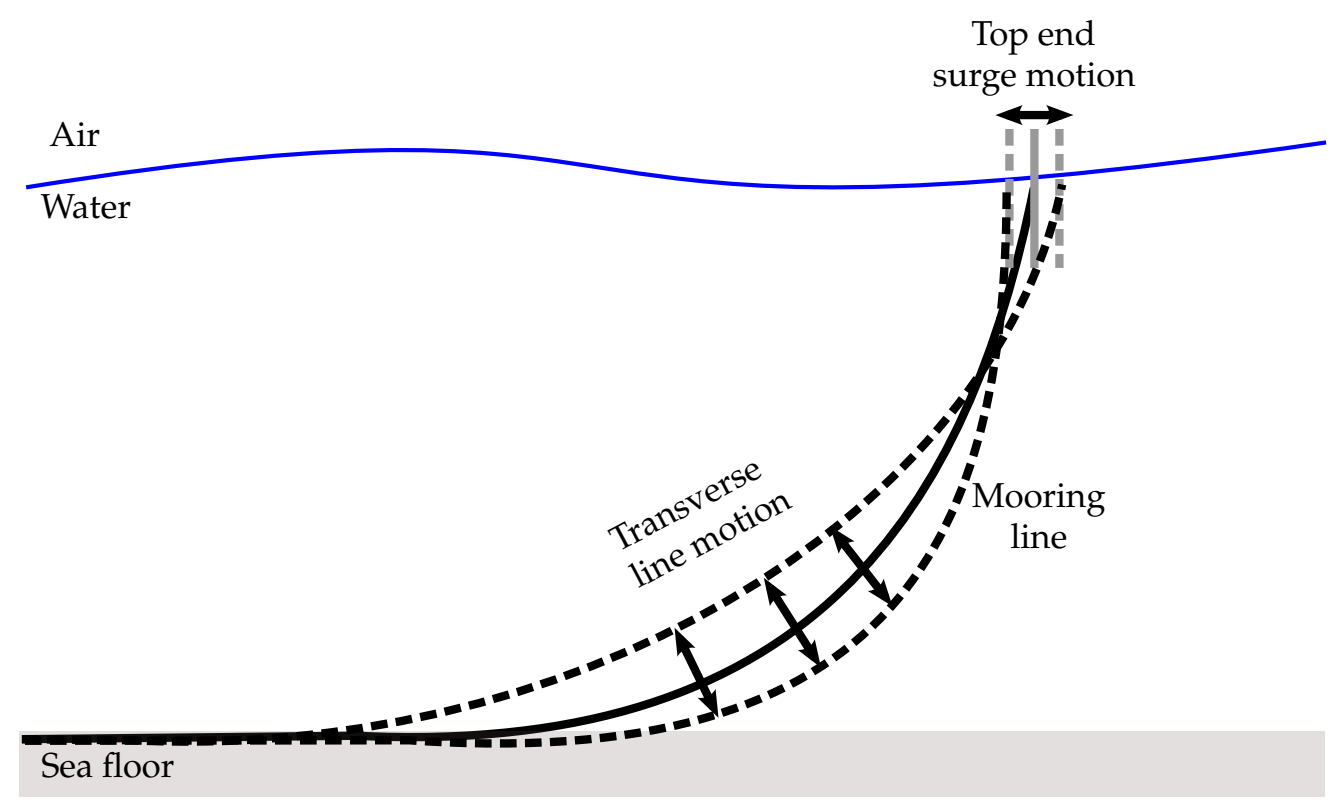

Figure 6. Large transverse mooring motion midline cause by small motion at the top end (Adapted from [51]).

\subsubsection{Inertia}

The inertia of the mooring system consists of the mass, $m$, of the mooring line, plus the added mass, $m_{a}$, of the surrounding fluid that the mooring line must also move. The inertia force can be calculated from Morison's equation [66]:

$$
F_{i}=\int_{\text {Anchor }}^{W E C} \frac{1}{4} \rho_{w} \pi D^{2}\left(1+C_{a}\right) a_{n}(s) d s
$$

where $C_{a}$ is the empirically derived added mass coefficient, and $a_{n}$ the magnitude of the normal component of the mooring line acceleration. 


\subsubsection{Resistance}

Mooring systems will have a resistive lossy effect, introducing damping on WEC motions, see Johanning et al. $[10,67]$, which is important to consider for estimating the energy production of the WEC in a realistic manner [24]. There are a number a damping mechanisms present in a mooring system, namely: hydrodynamic drag, vortex-induced vibrations (VIV), internal line damping and seabed interaction [12]. Here, the mooring line damping due to drag, vortex induced vibrations and internal line damping are outlined. Damping effects, due to the interaction with the sea floor, are addressed in Section 3.5.7.

Calculating mooring line damping has been of the focus of a number of studies, due to its important role in the LF motions of moored vessels and platforms. The thesis by Raaijmakers [68] focuses entirely on this subject. Historically, predictions of the LF dynamic behaviour of moored offshore structures assumed that the mooring system only influences the restoring force characteristics. However, the work by Huse [69] indicates that the mooring line provides up to $80 \%$ of the total damping for the surge motion of a floating offshore oil and gas platform. Huse [70] had previously proposed that drag forces, due to the motion of the mooring lines through the water, were the main source of energy dissipation, the reason being that a small offset of the top end can result in large transverse displacements along the mooring line (Figure 6), inducing considerable drag forces. A number of other authors, such as Liu [71], Bauduin and Naciri [72], and Lie et al. [73], have built upon the early work of Huse $[69,70]$, to improve the modelling of mooring line-induced damping.

Energy dissipation associated with catenary mooring line damping is studied by Johanning et al. [10], through a series of experimental tests, which concluded that mooring line damping increases in a nonlinear manner, as the line becomes increasingly taut. This is due to the aforementioned effect of small fairlead motions causing large transverse motions along the line (Figure 6), being more pronounced for taut cables than for slack cables. The experiments also show increasing levels of damping with increasing frequency, which becomes more relevant as the pretension increases. Webster [8] shows that the contributions of drag damping and internal damping compete: drag damping is associated with motions transverse to the mooring lines, while internal damping is associated with motions along the mooring line.

\section{Drag}

The drag force, $F_{D}(s)$, on the mooring line is proportional to the square of the mooring line velocity through the water. This relationship is expressed via Morison's equation:

$$
F_{D}(s)=0.5 \rho_{w} C_{D} D V(s)|V(s)|,
$$

where $C_{D}$ is the drag coefficient and the term $V(s)$ is the relative velocity between the water and the mooring line. However, depending on the level of modelling detail, sometimes the motion of the fluid is not taken into account, in which case $V(s)$ is simply the velocity of the line. Liu and Bergdahl [74] present a thorough treatment of drag, formulating it as:

$$
\begin{gathered}
F_{D n}(s)=0.5 \rho_{w} C_{D n} D\left(V_{C n}(s)+\dot{\eta}_{n}(s)-\dot{x}_{n}(s)\right)\left|V_{C n}(s)+\dot{\eta}_{n}(s)-\dot{x}_{n}(s)\right| \\
F_{D t}(s)=0.5 \rho_{w} C_{D t} D\left(V_{C t}(s)+\dot{\eta}_{t}(s)-\dot{x}_{t}(s)\right)\left|V_{C t}(s)+\dot{\eta}_{t}(s)-\dot{x}_{t}(s)\right|
\end{gathered}
$$

where the subscripts $n$ and $t$ denote the contributions normal and tangent to the mooring line line, respectively. $V_{C}$ is the current velocity and $\dot{\eta}$ is the wave excited water particle velocity.

The drag coefficient of the cable is therefore a critical parameter for the calculating the drag force, but is often chosen with some uncertainty [75]. For example, marine growth on the mooring line can 
change its drag properties. Recommended practice for selection of drag coefficients is reported in the offshore standard DNV-RP-F205 [50].

Internal Line Damping

The internal line damping, $F_{L D}$, caused by frictional forces within the line, is typically modelled as a linear dashpot, proportional to the strain velocity:

$$
F_{L D}=b_{I} \frac{d(\epsilon L)}{d t},
$$

where $b_{I}$ is the internal line damping parameter, whose value depends on the mooring line material and its construction. Weller et al. [76,77] document experiments on different mooring lines, providing datasets to facilitate the development of rope and mooring system simulation tools. The experiments involve sinusoidal loading of the lines, by anchoring one end and attaching the other end to an oscillating piston in a test rig, from which properties such as the damping rate and stiffness values can be determined. The damping rate is calculated via: $b=E_{d} /\left(\pi \omega X^{2}\right)$, where $E_{d}$ is the energy dissipated over each load-unload cycle, $\omega$ the angular frequency of the oscillation, and $X$ the amplitude of piston displacement.

\section{Vortex Induced Vibrations}

VIV refers to the dynamic loading from fluctuations in fluid pressure, caused by vortex formation in the wake of the mooring line. Analysis of the forces due to vortex shedding, and calculations of the induced loading, is complex and typically relies on computational fluid dynamics (CFD) or laboratory testing [78]. However, the frequencies at which VIVs occur can be relatively easily determined, from the Strouhal number.

The Strouhal number relates the vortex shedding frequency, $f_{v s}$, to the velocity of the ambient fluid flow, $u$, and a characteristic length dimension of the body (in this case the diameter of the mooring line). The Strouhal number is defined as: $S t=f_{v s} D / u$, and its value for a cylinder is between 0.17 to 0.20 over a wide range of flow velocities [68]. The phenomenon of 'lock-in' occurs when $f_{v s}$ becomes close to the natural frequency of vibration of the mooring line, causing a resonant response and increased levels of drag and internal line damping. Drag forces for wire lines, in particular, can be amplified by VIVs, whereas for chain the amplification is considered negligible [12,51]. An extensive investigation into VIV of cables in ocean currents is given by Vandiver [79].

\subsubsection{Interaction with the Sea Floor}

A significant length of catenary mooring lines is generally in contact with the sea floor. The interaction of the mooring line with the sea floor can result in energy dissipation through friction due to horizontal motion, kinetic energy loss from vertical motion, as the mooring line lays down on the sea floor, and then suction and static friction, as the cable is lifted from the sea floor. A popular approach to model the sea floor interaction, proposed by Webster [8], is to treat the sea floor as a very stiff distributed elastic support, as depicted in Figure 7. The support provides no local vertical force when the mooring line is more than one radius off the sea floor, but as the mooring line becomes closer to the bottom, the vertical force increases linearly. The spring constant of the elastic support is selected so that, when the mooring line is on the sea floor, the vertical force exactly balances the weight, in water, of the grounded mooring line. The energy dissipation is then modelled as a linear damper. Other studies to adopt versions of this approach include $[47,74,80-86]$. 


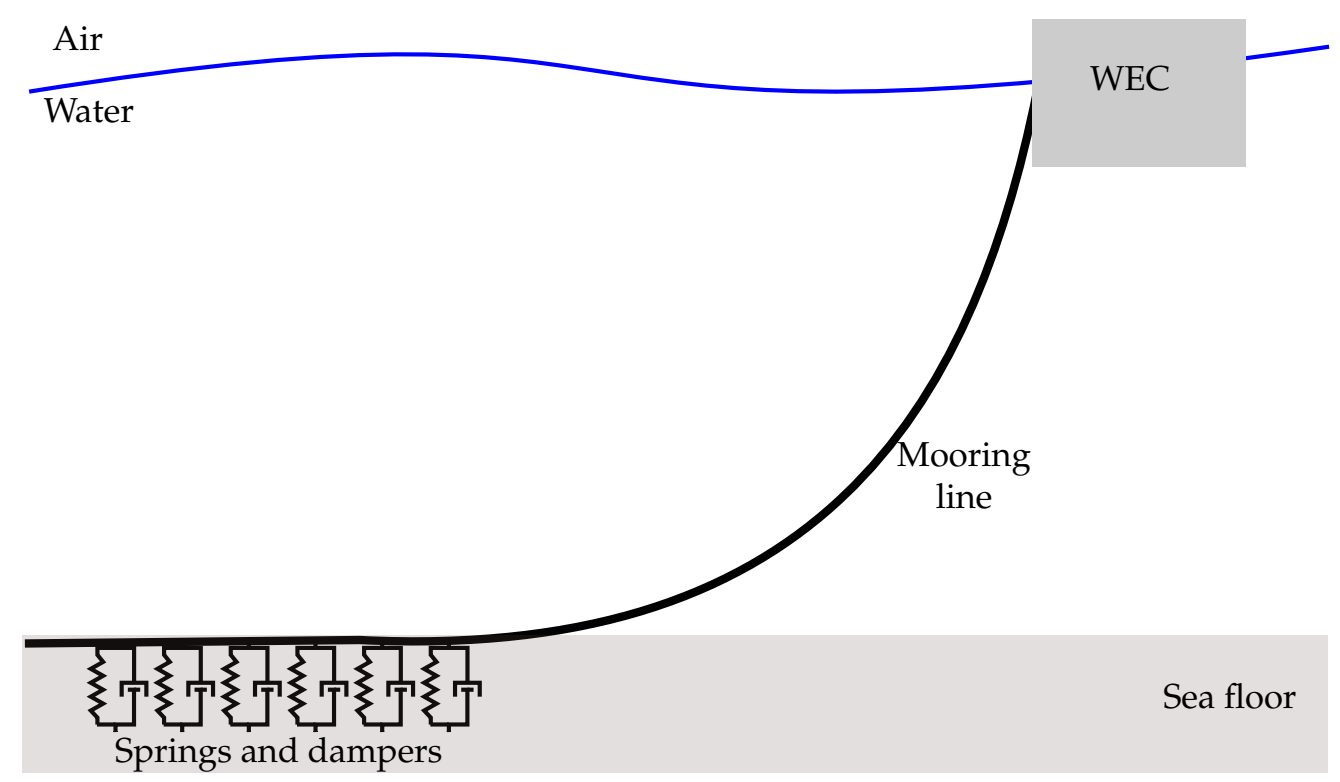

Figure 7. Elastic support approach of modelling the mooring line on the sea floor (from [8]).

\subsubsection{Snap Loads}

Snap or snatch loads are impulse-type mooring loads, with an amplitude much larger than static and dynamic mooring loads. Snap loads are caused when a mooring line becomes slack and is then suddenly re-tensioned, and are essentially discontinuous shock waves. For wave energy applications, the ratio between the horizontal motions of the floater and the water depth is usually large, thus increasing the probability of snap loads [34]. Additionally, PTO end-stop collisions for tautly moored WECs may also cause snap loads, as experimentally investigated by Hann et al. [87]. A good overview of snap loads in mooring systems for wave energy converters is detailed by Palm et al. [86]. The numerical mooring line model must have adequate spatial and temporal resolution to accurately capture snap loads, with appropriate numerical methods for this purpose reported by Vassalos and Huang [88] and Palm et al. [86].

\subsubsection{Bending and Torsional Effects}

The rotational degrees of freedom of the mooring line may also be subjected to damping and restoring forces, as the lines bend and twist. Bending and torsional effects are often considered for pipe-style moorings and risers found in offshore oil and gas platforms. However, for typical mooring line materials and configurations in WEC mooring systems, the bending and torsional effects are not significant and can be neglected for offshore renewable energy applications [89]. A sensitivity study was performed by Hall et al. [90], revealing that bending and torsional elasticity were of negligible importance to the mooring line tension responses for the three different stability classes of floating wind turbines investigated, regardless of load case. The results were the same whether the model used the significant bending stiffness of a wire rope or the nonexistent bending stiffness of a chain. Including bending and torsional effects into WEC MMs would therefore unnecessarily increase the model complexity and computational requirements, for negligible improvement in the accuracy of the results.

\subsection{Relevant Effects for Different Mooring Systems}

Table 3 compares the relevant effects for taut and slack mooring systems. 
Table 3. Comparison of effects for taut versus slack mooring systems.

\begin{tabular}{lll}
\hline Effects & Taut Mooring & Slack Mooring \\
\hline Restoring force & $\begin{array}{l}\text { - Axial elasticity of the line } \\
\text { - Coupled modes of WEC motion } \\
\text { due to inverse pendulum effect }\end{array}$ & $\begin{array}{l}\text { - Geometric compliance of catenary line } \\
\text { - Less coupling between WEC modes } \\
\text { of motion }\end{array}$ \\
\hline Damping & - Axial damping of the line & $\begin{array}{l}\text { - Axial damping of the line } \\
\text { - Increased drag from large velocities } \\
\text { mid-line }\end{array}$ \\
\hline Inertia & - Relatively light mooring line & $\begin{array}{l}\text { - Generally heavy mooring line } \\
\text { - Increased added mass from large } \\
\text { accelerations mid line }\end{array}$ \\
\hline \multirow{2}{*}{ Excitation } & - Waves & - Currents \\
& - Constrained WEC drift motion & $\begin{array}{l}\text { - Currents } \\
\text { - Significant WEC drift motion }\end{array}$ \\
\hline Sea bed interaction & - Less interaction with sea bed & - More interaction with sea bed \\
\hline Snap loading & - PTO end-stops & - Sudden transitions from slack to taut \\
\hline
\end{tabular}

\section{Model Types}

Mathematically describing the behaviour of the mooring system with relationships between the variables, parameters and environmental inputs, can be implemented with different model types, of varying degrees of complexity. These different model types can be classified as static, quasi-static or dynamic.

\subsection{Static Models}

A static model considers constant loads only, such as gravity, buoyancy, non-time varying current and wind, and mean wave-drift forces. Static analysis determines the equilibrium between the constant or mean environmental loads and the restoring force of the mooring lines on the WEC. Static equilibrium is determined in a series of iterative steps [91]:

1. At the start of the calculation, the initial positions of the WEC, and attached buoys and clump weights, are defined; these, in turn, define the initial positions of the ends of any lines connected to them.

2. The equilibrium configuration for each line is then calculated, with the line ends fixed.

3. The out-of-balance loads acting on each free body (WEC, buoy, weight, node, etc.) are then calculated and a new position for the bodies is estimated.

The process, steps 1-3, is repeated until the out of balance load on each free body is zero (up to the specified tolerance).

The results of the static analysis provide the equilibrium position of the WEC. The mooring system parameters, which can determine the equilibrium position, are [20]: (i) the mooring line pre-tension; (ii) the number of mooring lines, their orientation and material properties; and (iii) the length and dimension of these lines. By displacing the WEC through prescribed distances and calculating the static restoring load, the static analysis also provides relationships between the WEC displacement and the static restoring force of the mooring line, as depicted in Figure 8.

For the majority of systems, the static analysis process is very quick and reliable. As an example, static solutions for multi-segment mooring lines with attached buoys and weights are derived by Oppenheim and Wilson [92] and Smith and MacFarlane [93]. A static design is often used at the initial stage for conceptual design purposes, to identify initial components and configurations for further analysis. Additionally, the static analysis is often used to provide a starting configuration for dynamic simulations [91]. 

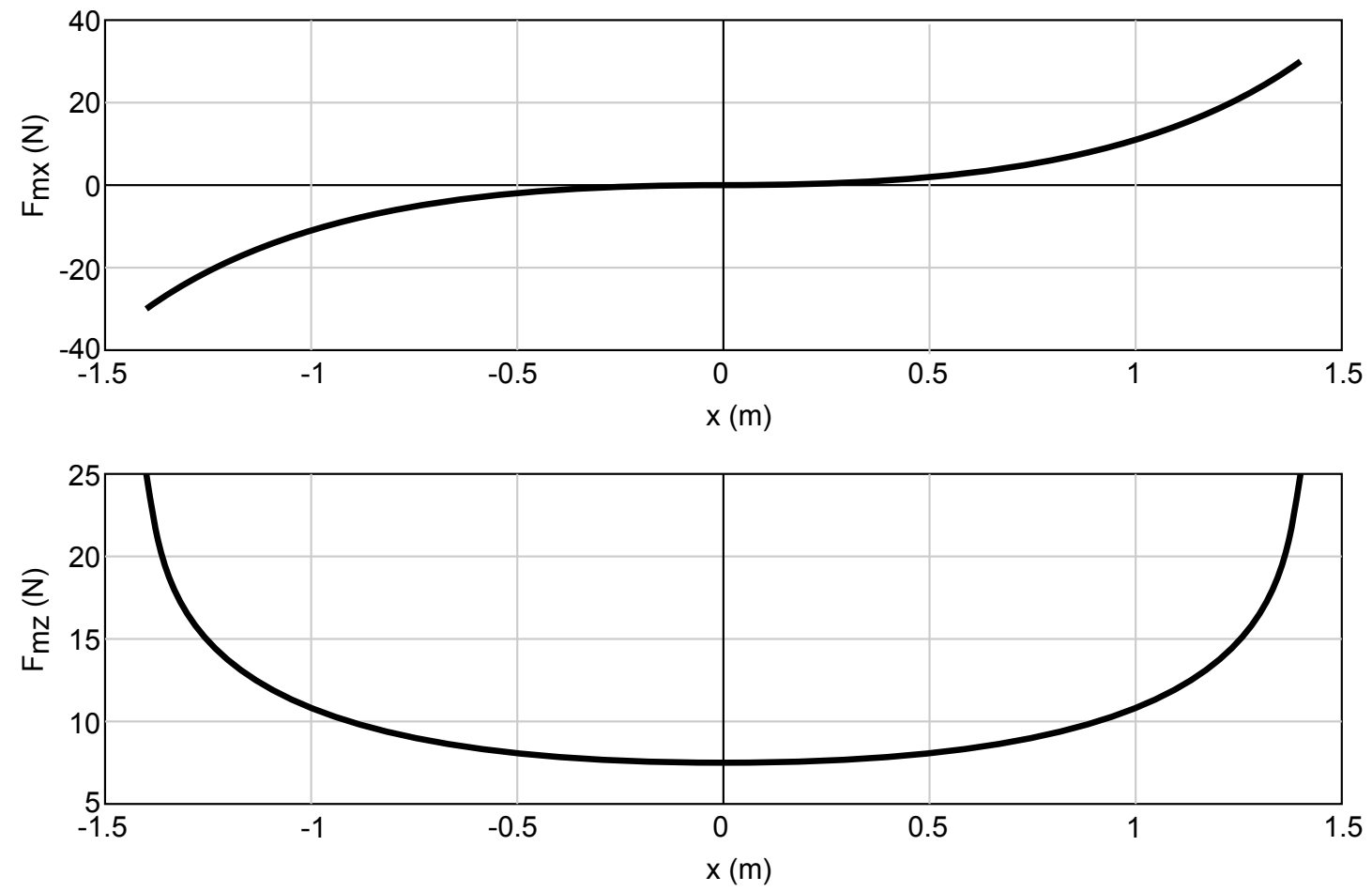

Figure 8. Static restoring force versus displacement (adapated from [19]).

\subsection{Quasi-Static Models}

The quasi-static approach assumes that the motion of the system is uniform and linear between two static positions, during a given time step for which the loads on the systems are assumed constant [29]. The dynamic effects on the mooring system are ignored by this method, omitting the motion dependency of mass, damping and fluid acceleration on the system [20]. Quasi-static models derive the mooring line shape and tension from the catenary formulations, based on the assumption that the line is in static equilibrium in each time step, that inertia effects can be neglected and that the line profile is reasonably well described by the catenary equations [72]. The mooring force on the WEC therefore consists only of the position dependent static restoring force, shown for example in Figure 8. Implementation of quasi-static models for offshore mooring applications, and a review of their development, can be found in $[72,84,94,95]$ and, for the specific case of wave energy applications, in Nava et al. [96].

The main disadvantage of quasi-static models is that they neglect hydrodynamic and inertial forces on the line, which can affect the WEC response and are especially important for predicting the mooring loads [89]. Additionally, for point absorber type WECs, which respond quickly due to WF motions, a situation similar to that illustrated in Figure 9 could occur [29], where the top of the line follows the WEC motion but further down the line there is a delayed response, violating the catenary profile assumptions of a quasi-static model. An illustration of the large possible discrepancies, between the predicted outputs from a quasi-static and a dynamic MM, can be seen in the various graphs of calculated displacements and tensions in Yang et al. [97]. 


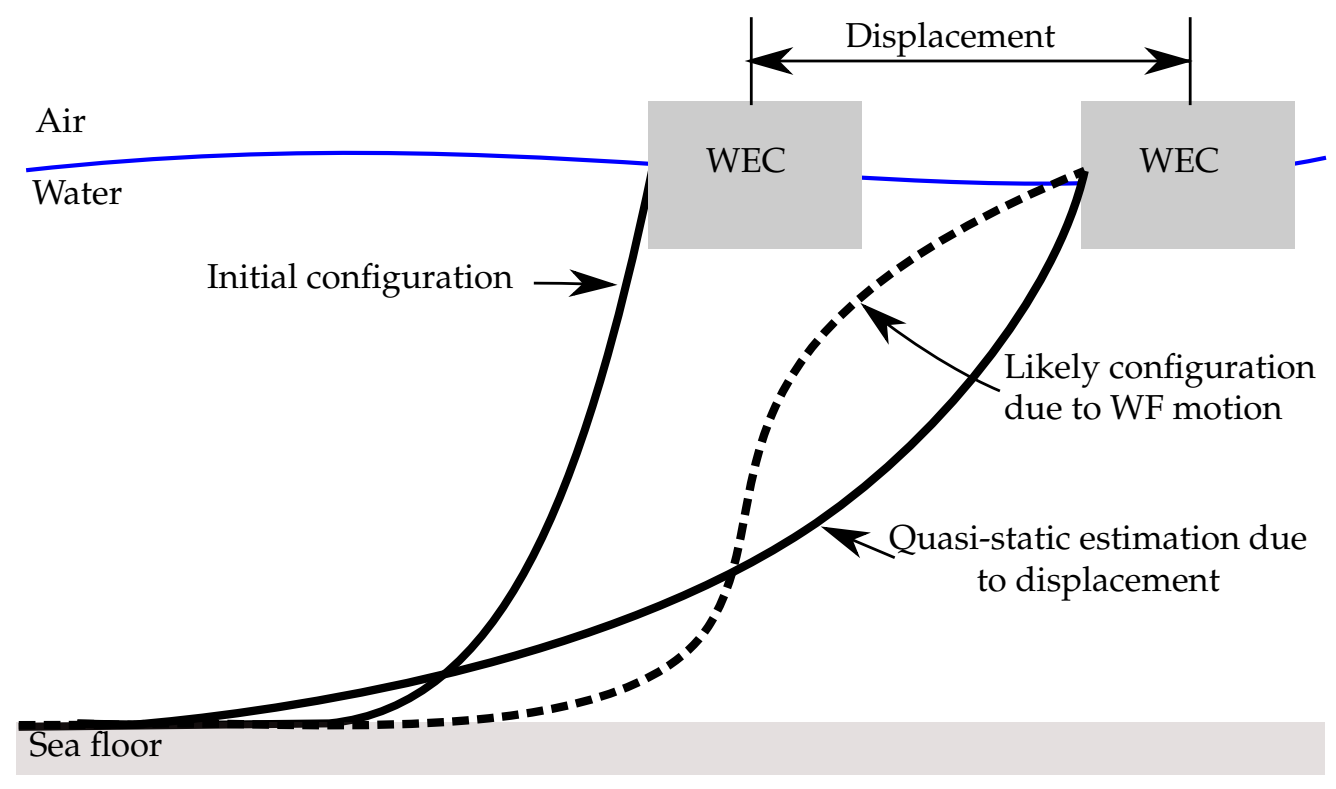

Figure 9. Differnce between the quasi-static and dynamic mooring models (adapted from [29]).

\subsection{Dynamic Models}

Like most mechanical systems, the dynamics of the mooring line are formulated using Newton's second law (of motion), where the resulting motions are due to the forces acting on the body. The mooring line dynamics are governed by the following equation [98]:

$$
\rho_{m} \frac{\delta^{2} \mathbf{r}}{\delta t^{2}}=\frac{\delta}{\delta s}\left(\frac{T}{1+\epsilon} \frac{\delta \mathbf{r}}{\delta s}\right)+\mathbf{f}(1+\epsilon)
$$

where $f$ is a vector comprising the external forces acting on the line. Solutions to Equation (19) can be difficult to obtain, except under simplified specific cases. An example of such a simplified case is given by Aranha and Pinto [99], where an algebraic approximation is derived for an expression of the dynamic tension under sinusoidal excitation. Otherwise, in general, a solution to these equations must be obtained either by linearising the model or by employing numerical techniques to approximate the governing nonlinear differential equations [64]. The numerical approximations are obtained via a spatial discretisation of the mooring line to form a set of ordinary differential equations (ODEs), which are subsequently discretised in time and solved by an integration algorithm. A dynamic simulation will often use a static analysis solution as its initial configuration and then evolve forward in time from there.

The following subsections detail the different spatial and temporal discretisation methods commonly used for nonlinear dynamic MMs. A linearisation approach is then outlined, which allows a frequency-domain representation of the mooring system. Obtaining computationally efficient dynamic mooring system models, via system identification techniques, is then presented. Lastly, the coupling between the dynamic models for the WEC and mooring system is discussed.

\subsubsection{Discretisation}

Walton and Polachek [44] published the first treatment of discretised mooring line modelling by formulating the equations of motion for discrete elements, with hydrodynamic drag and added mass forces applied uniformly over each element. Centered finite differences were used to discretise the time derivatives and evolve the solution forward in time. Polachek et al. [45] later added cable extensibility, thereby offering a thorough method for treating the nonlinear mooring line dynamics. Their discretisation method would nowadays be categorized as a lumped mass method, whereby the 
mass and externally applied forces are lumped at a discrete number of points/nodes, which are connected by massless springs [65]. The lumped mass method and other spatial discretisation approaches, such as finite differences and finite element methods (FEMs), are outlined in this subsection. A comparison of these different spatial discretisation approaches is given by Mascoila et al. [100], who explore the features of the various models and weigh the advantages of each.

\section{Lumped Mass}

The lumped mass method involves lumping of all the effects of mass, external forces and internal reactions at a finite number of nodes, $N$, along the line, as depicted in Figure 10. This procedure implies that the behaviour of a continuous line is modelled as a set of concentrated masses connected by massless springs [101]. By applying the equations of dynamic equilibrium and continuity (stress/strain) to each mass, a set of discrete equations of motion is derived. The lumped mass method is shown to have the advantage of a strictly diagonal mass matrix, eliminating the requirement of added computation for matrix inversion [100]. Detailed descriptions of example usage of lumped mass MMs can be found in $[81,89,101-104]$ and, for the specific case of WEC moorings, in Vissio et al. [19].
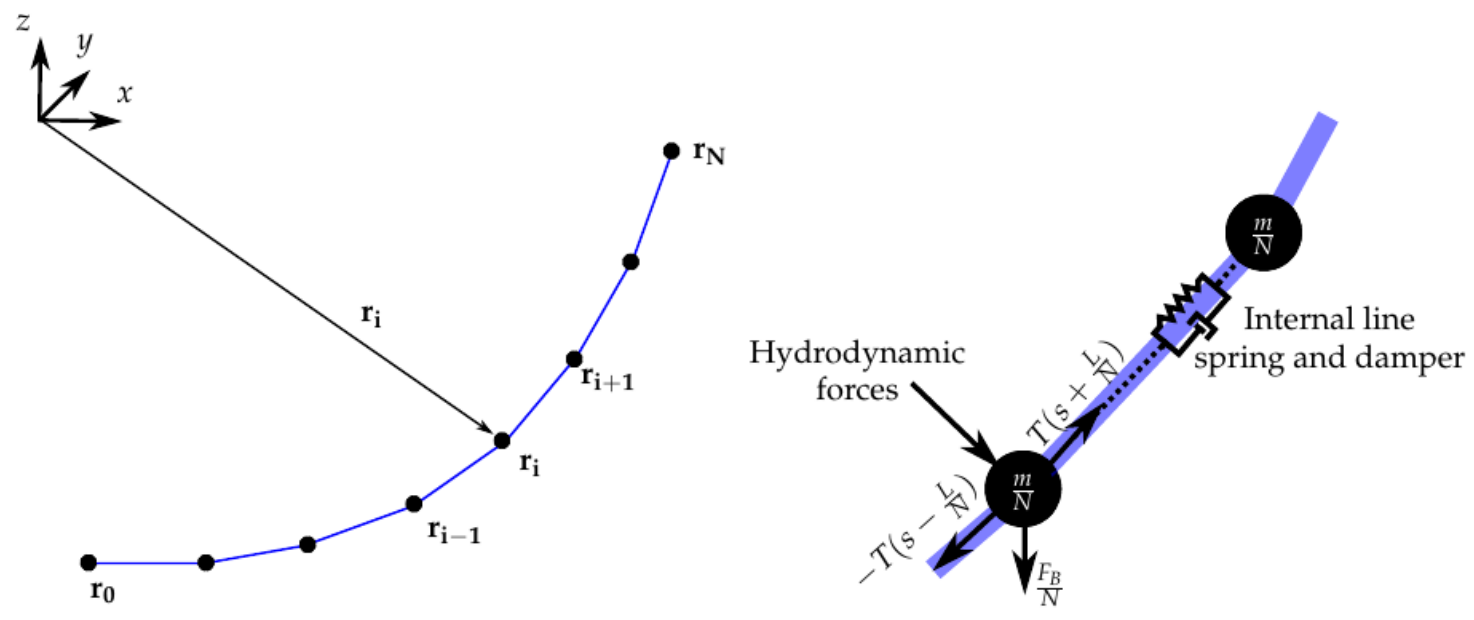

Figure 10. Depiction of lumped mass approach (adapted from [89]).

\section{Finite Differences}

The finite difference approach differs from lumped mass methods by using an infinitesimally small differential element, rather than a finite discrete element. Spatial derivatives may then be treated algebraically as:

$$
\frac{\delta y}{\delta x} \approx \frac{y^{i+1}-y^{i}}{\Delta x} \approx \frac{y^{i}-y^{i-1}}{\Delta x} \approx \frac{y^{i+1}-y^{i-1}}{2 \Delta x},
$$

using forward, backward or centred finite differences, respectively. Detailed descriptions of implementing finite differences for mooring line, cable and/or riser models are given in [47,105-107] and, for the specific case of WEC moorings, in Cerveira et al. [85].

\section{Finite Element}

The FEM also discretises the mooring line into small differential elements; however, whereas the finite differences method uses the differential form of the governing equations, the FEM uses their integral form counterpart. Variables internal to each element are then described via basis/interpolation functions and the integrals are solved using numerical integration techniques. Therefore, unlike the finite difference method, which estimates the spatial gradients in the governing partial differential equation (PDE) with first-order finite difference functions, the FEM eliminates the spatial gradients by approximating the PDE locally by a set of ordinary differential equations (ODEs), similar to the 
lumped mass method. Whilst lumped mass models must place all masses at discrete nodes, FEMs can derive the governing equations with an integration of the mass over the entire element, leading to a "consistent" mass formulation [80]. Although the resulting mass matrix achieves an upper and lower bandwidth of two, compared to the more computationally efficient strictly diagonal matrix for the lumped mass formulation [100], the FEM is able to produce accurate results with a smaller number of elements compared to the lumped mass formulation. Examples of different solution methods include: collocation [14], Galerkin [88,108,109], and discontinous Galerkin [110] methods. A detailed description of finite element modelling for mooring lines is given in [108-111] and, specifically for the case of mooring systems for WECs, in Palm [112].

\section{Other Spatial Discretisations}

Whilst the lumped mass, finite differences and FEMs are the most established and popular discretisation schemes, a number of other methods have been used for mooring lines and are detailed here. Winget and Huston [113] and Kamman and Huston [114] utilise a finite segment scheme, consisting of a series of ball-and-socket connected rigid rods, to discretise a mooring cable. Nichol et al. [115] implement a finite segment model for the mooring system of floating tidal energy devices. Garrett [116] utilises a similar scheme consisting of elastic rods. Filipich and Rosales [117] model a chain mooring line, by discretising the chain into its individual links.

Temporal Discretisation

The spatial discretisation of a mooring line produces a series of ODEs, which are then solved and advanced in time by an integration algorithm. Most temporal integration schemes are a member of the Newmark family [118], which is characterized by the following equations [119]:

$$
\begin{gathered}
\mathbf{x}_{n+1}^{*}=\mathbf{x}_{n}^{*}+\Delta t \dot{\mathbf{x}}_{n}^{*}+\frac{\Delta t^{2}}{2}\left[(1-2 \beta) \ddot{\mathbf{x}}_{n}^{*}+2 \beta \ddot{\mathbf{x}}_{n+1}^{*}\right] \\
\dot{\mathbf{x}}_{n+1}^{*}=\dot{\mathbf{x}}_{n}^{*}+\Delta t\left[(1-\gamma) \ddot{\mathbf{x}}_{n}^{*}+\gamma \ddot{\mathbf{x}}_{n+1}^{*}\right]
\end{gathered}
$$

where $\Delta t$ is the time step; $\mathbf{x}_{n+1}^{*}, \dot{\mathbf{x}}_{n+1}^{*}$ and $\ddot{\mathbf{x}}_{n+1}^{*}$ are stepwise approximations to the unknown nodal values of the displacement, velocity and acceleration, respectively, at time $\Delta t(n+1) ; \gamma$ and $\beta$ are adjustable parameters defining each particular member of the Newmark family. Implicit algorithms, such as the trapezoidal rule ( $\gamma=0.5, \beta=0.25)$, are better for inertial problems, where the dynamic response is dominated by mode shapes with higher period values. Explicit algorithms such as the central difference method $(\gamma=0.5, \beta=0)$ are more adequate for transient problems [119]. Explicit methods calculate the state of a system at time $t_{n+1}$ from the state of the system at the time $t_{n}$, while implicit methods use the state of the system at $t_{n}$ and $t_{n+1}$. The explicit scheme is robust, but may be slow because it requires a very short time step, while the implicit scheme is faster but may produce inaccurate results [35].

The history, development and usage of the different numerical schemes used for the temporal discretisation and integration of mooring line dynamics is outlined in Gobat [65] and the references therein. Thomas [13] performs an investigation of time integration schemes for mooring line dynamics and gives a thorough review of the different available schemes and their derivations. Hearn et al. [120] examines the influence of using different time integration schemes to solve the dynamic equations of motion applicable to a mooring line.

Finite-difference models discretise the ODEs in both space and time, thereby formulating an inherent time-stepping approach. Lumped-mass models, however, only discretise the ODEs in space, and therefore leave continuous time derivatives, requiring an external integration scheme to advance the model in time [89]. 
The most popular finite difference scheme is the box method, depicted in Figure 11, in which the governing equations are discretised on the half-grid point, in both space and time [121]. By applying the discretisation on the half-grid points, with spatial and temporal averaging of adjacent grid points, the box method is second-order accurate [121]. Cable dynamics applications that do not employ the box method, often use temporal integration, such as backward difference, which is only first-order accurate, or the generalized trapezoidal rule, which is second-order accurate only in its most unstable form [121]. The box method is unconditionally stable for linear problems, but has no numerical dissipation and is susceptible to Crank-Nicholson noise [121]. Therefore, Gobat [65] demonstrates that the box method is seldom the best choice of temporal discretisation scheme for the cable dynamics problem. Koh et al. [122] also come to this same conclusion and propose a modified box method that uses backward difference for the temporal discretisation. However, Gobat [65] combines the box method spatial discretisation with the generalized- $\alpha$ method for temporal integration. Compared to other schemes, commonly employed for the temporal integration of the cable dynamics equations, including the box method, trapezoidal rule, backward difference, and Newmark's method, the generalized- $\alpha$ algorithm has the advantages of second-order accuracy, controllable numerical dissipation, and improved stability, when applied to the nonlinear problem.

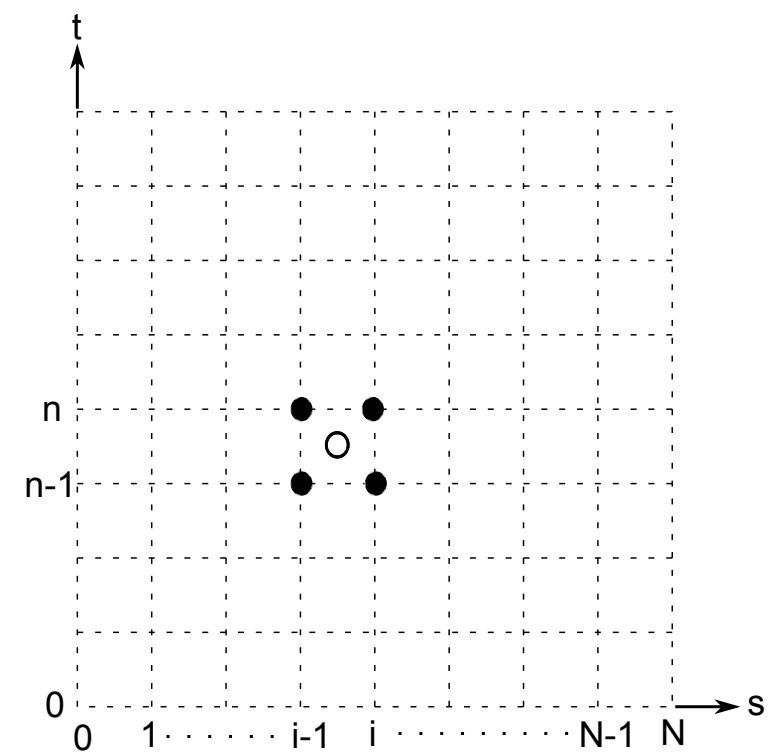

Figure 11. Depiction of the box method finite difference scheme (adapted from [65]).

\subsubsection{Linearisation and Frequency Domain Models}

Linear models are computationally simpler than their nonlinear counterparts and offer the advantage of frequency domain analysis. Therefore, it is often desirable to linearise the governing dynamics to simplify the analysis and reduce the computational requirements of the model. For example, power production estimates for a WEC require simulating the WEC operation across a wide range of sea states, which can be computationally prohibitive in the time domain and is therefore typically calculated in the frequency domain. For example, Cerveira et al. [85] argue that during power production conditions, the WEC motions are of relatively small amplitude, therefore it is possible to approximate the nonlinear mooring characteristics to the linear order. Cerveira et al. [85] model the mooring system by adding linear mass, damping and stiffness coefficients to the linear equations of motion for the WEC, which are then solved in the frequency domain.

A frequency domain methodology is presented by Fitzgerald and Bergdahl [123] to evaluate the effect of moorings on WEC power extraction. The nonlinear mooring dynamics are calculated numerically in the time domain, for different conditions and then approximated to the linear order. The approximation is considered to be valid for small motion amplitudes and load induced 
tensions that are small relative to the equilibrium pretension. A similar approach is taken by Spanos et al. [55,124,125], who use a statistical linearisation scheme. A time-domain analysis of the nonlinear behavior of the system is performed, and then the mean-squared error between the nonlinear system and the linear one is minimised to determine, iteratively, the effective linear stiffness and damping of the mooring system.

Other examples of linearised MMs for WECs exist. Bachynski et al. [33,126] perform a simple frequency domain analysis on a point absorber WEC, model the mooring as additional linear restoring force and then add the mass of the mooring lines to the mass of the WEC mass. In Bachynski et al. [127] and Zaroudi et al. [128], linearised stiffness coefficients for the mooring system are computed using the method from Jain [63], which allows fast calculation of the stiffness coefficients of catenary lines, for small floater motions, as a function of the pretension, cable weight in water per-unit arc length, fairlead and anchor locations, and line angle at the seabed. Vincente et al. [129] use a frequency domain analysis to investigate the mooring effects on an array of WECs, modelling the interbody and bottom mooring lines as linear springs/dampers.

For general offshore applications, established techniques of statistical linearisation have been employed to linearise the nonlinearities in the restoring forces and drag, based on minimizing the mean-squared error and assuming Gaussian statistics [130]. A treatment of the current and seabed friction in the frequency domain, obtained via statistical linearisation, is presented by Liu and Bergdahl [74]. In Sarkar and Taylor [131,132], the nonlinear drag is linearised by preserving the energy dissipation over each cycle. Similarly, Lie et al. [73] identify mooring line damping coefficients from finite element time domain simulations, using a method based on energy dissipation. Other papers which include linearised, or frequency domain treatment, of the dynamic mooring system model include $[57,81,106,107,116,133-139]$.

However, although linear models and frequency domain techniques offer computationally efficient MMs, the necessary linearisation of nonlinear terms can induce errors in final predictions [9]. As shown in [140-144], complex nonlinear responses are found in mooring systems with geometric nonlinearities and nonlinear drag, with multiple coexisting solutions and existance of chaotic explosions, which could not be predicted by equivalent linearisation methods. Additionally, Van den Boom [101] shows that dynamic tension amplification is strongly influenced by nonlinearities, due to catenary effects, elasticity and drag, and therefore would not be captured in frequency domain models. The MM comparative study by Brown et al. [12] reveals that line tension and damping results, using nonlinear time domain methods, were generally in good agreement with each other. In contrast, results generated using frequency domain techniques, and particularly damping results, showed large scatter and significant differences, in comparison to their nonlinear time domain counterparts.

\subsubsection{System Identification}

While the linear models in Section 4.3.2 overcome the computational demands and complexity of the nonlinear, spatially disretised, time domain simulations in Section 4.3.1, the accuracy of the linear models is limited and is unacceptable for many situations. Another modelling approach, described in this section, is that of system identification, where computationally efficient nonlinear parametric models are identified from input/output data of the system behaviour obtained from high-fidelity numerical simulations. The computationally expensive high-fidelity numerical simulations therefore only need to be performed once, and then the identified nonlinear parametric models can reproduce the system behaviour in future simulations at a fraction of the computational time. This approach has been used, for example, for WEC hydrodynamics, by using computationally expensive CFD experiments to produce realistic data of the WEC behaviour, which is then used to identify nonlinear parametric hydrodynamic models [145].

System identification has been used to obtain computationally efficient MMs for general offshore mooring applications. For example: Pascoal et al. $[146,147]$ represent the mooring force by a Taylor series and identify the parameters using data from a lumped mass time domain simulation. Umar and 
Datta [148] and Murhpy et al. [149] represent nonlinear restoring force terms with polynomials, whose coefficeints are identified by fitting the polynomials to the restoring force versus displacement curves obtained from numerical calculations. The dynamics of the mooring system have also been replicated by Volterra models $[150,151]$ and neural networks [152-157].

Physical experiments have also been used to provide the identification data, instead of high fidelity numerical simulations. For example, Narayanan et al. $[158,159]$ and Raman et al. $[160,161]$ identify the polynomial coefficients for nonlinear restoring force curves from physical experiments. Gobat and Grosenbaugh [162] develop a frequency domain model for dynamic tension identified from experimental data. Other examples of system identification used on experimental data to identify MMs include Grosenbaugh et al. [163] and Gottlieb et al. [164]. The work by Weller et al. [76] aims to provide datasets, on internal line damping properties obtained from physical experiments, to aid in the identification and development of MMs.

An example of the system identification approach, applied to WEC moorings, is presented by Cerveira et al. [85], where a reduction in model complexity for the mooring system dynamics was required because using the fully nonlinear mooring dynamics code was prohibitively time consuming, and prone to collapse, due to numerical instabilities. The mooring line force on the WEC was approximated by a Taylor series, where the coefficients were identified from data produced by simulations from the fully nonlinear mooring dynamics code.

\subsubsection{Coupled or Uncoupled Models}

A WEC and its mooring lines are intrinsically a coupled system; the dynamics of the WEC affect the mooring dynamics and vice versa. This requires a dynamic analysis method that can iterate the solution for the WEC and the mooring lines until they converge on a compatible solution [29]. However, to save on computation, uncoupled analyses were traditionally performed, by solving the WEC and mooring dynamics separately. An early implementation of the coupled approach was performed by Ormberg and Larsen [165], where motions and mooring line tensions from physical model tests and simulations, using coupled and uncoupled procedures, were compared. The main conclusion was that the traditional uncoupled approach may be severely inaccurate, especially for floating structures operating in deep waters.

The uncoupled analysis is usually undertaken in two steps. The first step involves the computation of the WEC motions, either without any influence from the moooring system included or only with quasi-static restoring forces from the moorings. The second step then involves applying the precalculated WEC motions, as boundary conditions at the top end of the mooring, to perform a dynamic analysis of the mooring system. The uncoupled approach reduces the complexity of the numerical simulation and often offers greater numerical stability, compared to the coupled approach [166].

In the coupled approach, the equations of motion of the WEC and mooring lines are solved simultaneously. Gao and Moan [24] prescribe the following procedure for a coupled mooring analysis: a static equilibrium is first found by a nonlinear static analysis, considering only the mean environmental forces. Mean offset and mean mooring line tension are then obtained. Next, the motion of the WEC and the mooring line tension are solved simultaneously, under the dynamic wave and wind forces, using an appropriate time integration scheme. However, two types of coupling schemes can be performed; weak coupling and strong coupling.

- Weak coupling: At each time step, for the equations of motions of the WEC, one (or more) steps of a nonlinear dynamic analysis of the mooring lines is performed, using the WEC displacement from the previous time step at the fairlead of each line. The resulting forces and moments, at the top of the lines, are then included in the forces acting on the WEC, at the current time step.

- Strong coupling: At each time step, the dynamic analysis of the mooring lines is performed, where the WEC is considered a "node" of this model, alongside the other discretised nodes of the mooring lines. 
Jacob et al. [167] present results of case studies employing the weak and strong coupling formulations, and the behavior of these formulations is compared, in terms of their accuracy, computational performance, and applicability to different types of offshore systems. Rodrigues et al. [119] show that the weak coupling scheme provides very good results, with considerably better efficiency than the strong coupling scheme.

Other examples of coupled analyses include Tahar and Kim [168], where the dynamics of hull, mooring lines, and risers were solved simultaneously in a combined matrix at each time step. Idris [169] performs coupling between a buoy and cable by adopting the buoy equations of motion as boundary conditions, at one end, for the mooring problem. Garrett [116] details a coupling scheme for moorings and risers for use with offshore floating platforms.

The coupling of the WEC and the mooring lines, discussed in this section, is referred to as Type 1 coupling by Low and Langley [130]. Another type of coupling to be considered in the mathematical modelling of mooring systems, termed Type 2 coupling by Low and Langley [130], is the coupling between the system response at different time scales, namely the mean offset, the response at the incident WF, and the LF second order wave drift motions. For example, the dynamic response of the mooring system at the WF is influenced by the catenary profile of the mooring line which changes with the LF drift motion, and the damping of the LF drift motions is influenced by the WF motions. Type 2 coupling is discussed in further detail in Section 7.3.

\section{Software Packages}

There exist numerous software packages that implement MMs for offshore applications. The various software packages used within the publications reviewed in this paper are listed in Table 4, and are grouped into commercial, open-source and in-house packages. The type of models available in each software package are indicated in the table, along with the references reporting on the targetted usage of each software package. Some software packages are able to simulate the WEC hydrodynamics as well as the MMs, which is also indicated in the table. However, Rhinefrank et al. [170] note that, due to the specific nature of ocean energy harvesting devices, off-the-shelf software packages often need to be supplemented with custom made numerical approaches, an example of which would be a PTO model.

Table 4. Software packages for mathematically modelling mooring systems ( $\mathrm{S}=$ Static, $\mathrm{QS}=$ Quasi-Static, TD = Time Domain, FD = Frequency Domain, WEC = WEC dynamics $)$.

\begin{tabular}{|c|c|c|c|c|c|c|}
\hline Software & $\mathrm{S}$ & QS & TD & FD & WEC & Used by \\
\hline \multicolumn{7}{|l|}{ Commercial: } \\
\hline - AQWA [61] & $\mathrm{x}$ & $\mathrm{x}$ & $\mathrm{x}$ & $\mathrm{x}$ & $\mathrm{x}$ & {$[18,27,149]$} \\
\hline \multicolumn{7}{|l|}{ - DNV Sesam } \\
\hline${ }^{*}$ Deep C [171] & \multirow{5}{*}{$\mathrm{x}$} & & \multirow{5}{*}{$x$} & \multirow{5}{*}{$\mathrm{x}$} & $\mathrm{x}$ & \multirow{5}{*}{$\begin{array}{l}{[17,24,38]} \\
{[24,73]} \\
{[5,38,153,174,175]} \\
{[18,38]} \\
{[153,175,178,179]}\end{array}$} \\
\hline * MIMOSA [172] & & & & & $\mathrm{x}$ & \\
\hline * RIFLEX [173] & & & & & & \\
\hline * SIMA [176] & & & & & $x$ & \\
\hline * SIMO [177] & & & & & & \\
\hline - FLEXCOM [180] & \multirow{3}{*}{$\begin{array}{l}x \\
x\end{array}$} & \multirow[t]{3}{*}{$x$} & $\mathrm{x}$ & \multirow[t]{3}{*}{$x$} & $\mathrm{x}$ & [39] \\
\hline - OrcaFlex [91] & & & $\mathrm{x}$ & & $\mathrm{x}$ & \multirow{2}{*}{$\begin{array}{l}{[10,11,16,18,35,41,81,170,181-188]} \\
{[83,90,190]}\end{array}$} \\
\hline - Proteus DS [189] & & & $\mathrm{x}$ & & $\mathrm{x}$ & \\
\hline \multicolumn{7}{|l|}{ Open-source: } \\
\hline - MAP [191] & \multirow{2}{*}{\multicolumn{2}{|c|}{$x$}} & & & & {$[95,100]$} \\
\hline - MoorDyn [192] & & & $\mathrm{x}$ & & & [19] \\
\hline \multicolumn{7}{|l|}{ In-house: } \\
\hline - AQUA-FE & & & $\mathrm{x}$ & & & {$[62,193]$} \\
\hline - MooDy [194] & & & $\mathrm{x}$ & & & {$[7,17,195]$} \\
\hline - MoDEX [196] & & & $\mathrm{x}$ & & & {$[22,32,123]$} \\
\hline - WHOI Cable [197] & $\mathrm{x}$ & & $\mathrm{x}$ & & & {$[65,80]$} \\
\hline
\end{tabular}


The commercial packages include AQWA, DNV SESAM, Flexcom, OrcaFlex and Proteus-DS. AQWA was developed by ANSYS and provides a toolset for investigating the effects of environmental loads on floating and fixed offshore structures. SESAM is a software suite for structural and hydrodynamic analysis of ships and offshore structures, originally developed by the Norwegian University of Science and Technology and later bought by Det Norske Veritas (DNV). SESAM consists of several modules, such as Deep C, MIMOSA, RIFLEX, SIMA and SIMO. The SESAM modules are compared by Chrolenko [198] for the dynamic analysis and design of mooring lines. Flexcom is a structural analysis software package, developed by MCS Kenny, whose engineers are immersed in the offshore oil and gas industry. Flexcom offers a broad range of capabilities for modelling and analysing vessel and mooring behaviour due to relevant environmental loading. OrcaFlex is a software package, developed by Orcina, for the dynamic analysis of offshore marine systems. OrcaFlex has the capability to simulate the WEC and mooring coupled dynamics using both nonlinear time domain and linear frequency domain analysis, or can be used as a library, allowing integration into third party software and automation possibilities. Table 4 shows that OrcaFlex is by far the most popular software package used in the publications reviewed in this paper. Proteus-DS is a time-domain simulation tool, developed by Dynamic Systems Analysis Ltd, used to analyse and design a variety marine, offshore and subsea systems and technologies using a variety of hydrodynamic and finite-element analysis techniques, and has been used to simulate WEC dynamics.

Two open-source software packages were identified, MoorDyn and Mooring Analysis Program (MAP). MoorDyn is an open-source lumped-mass mooring line model, developed at the University of Victoria, Canada, that supports arbitrary line interconnections, clump weights and floats, and different line properties. The model accounts for internal axial stiffness and damping forces, weight and buoyancy forces, hydrodynamic forces from Morison's equation, and vertical spring-damper forces from contact with the seabed. MAP is developed by the National Renewable Energy Laboratory (NREL) in USA, and is designed to model the static and dynamic forces of a mooring system. The implementation of a multi-segmented, quasi-static mooring model in MAP is investigated by Masciola et al. [95]. Seabed contact, seabed friction, and externally applied forces can be modeled with this tool, and it allows multi-element mooring systems, with arbitrary connection configurations, to be analysed. NREL, in partnership with Texas A\&M University, have also developed an open-source dynamic FEM mooring model, FEAMooring [199], for the analysis of floating offshore wind turbines, which may also prove useful for WEC applications.

The in-house software packages identified are: AQUA-FE, MooDy, MODEX and WHOI cable. AQUA-FE is a finite-element program developed at the University of New Hampshire to model partially and completely submerged structures and their moorings in the open ocean, and has mostly been applied to mooring systems for aquaculture applications. MooDy is a software application developed by the Department of Shipping and Marine Technology at Chalmers University of Technology, Sweden, for computing cable dynamics. MooDy was created as a tool for in-depth analysis of the tension force propagation in mooring cables and is designed to accurately capture the effect of snap loads. MooDy is based on a FEM with high-order polynomial basis functions and spatial discretisation using the local discontinuous Galerkin method. Chalmers University of Technology also developed MODEX, which is an older program that uses a FEM, with rod elements, to discretise a submerged cable. WHOI cable is proprietary software of Woods Hole Oceanographic Institution, built upon the groundwork from Howell [106] and Tjavaras [200], consisting of a collection of programs for nonlinear cable mechanics designed specifically to solve for typical oceanographic mooring systems.

Apart from the available software packages, it is, of course, possible to implement MMs by programming the governing equations in general purpose software environments. For example, Martinelli et al. [201] present a model for the dynamic simulation of a catenary mooring line, by implementing the equations describing the dynamic movements of a chain in Comsol Multiphysics, and shows that the solution fully agrees with experimental measurements. 


\section{Applications in WEC Analysis}

Mathematical models for WEC mooring systems are important for numerous applications in the design, analysis and optimisation of WEC systems, such as:

- Mooring design

- Analysis of mooring line fatigue

- Analysis of extreme loads

- WEC simulation

- WEC control design and evaluation

- WEC array layout

Each of these applications is presented in more detail within this section. A tabulated literature review is collated for each application, listing the type of WEC, mooring system and models used in each reference. (Note: For brevity, the following abreviations are used in Tables 5-10: $\mathrm{TD}=$ Time Domain, FD = Frequency Domain, $\mathrm{QS}=$ Quasi-Static, PA = Point Absorber, M. = Mooring, $\mathrm{NL}=$ Nonlinear, $\mathrm{L} .=$ Linearised, $\mathrm{RF}=$ Restoring Force) .

\subsection{Mooring Design}

The mooring design must be an integral part of the overall WEC design, because the mooring system not only represents a large fraction of the capital costs, but can also influence the WEC performance in both operational and survival modes. The objective is to find design solutions to mitigate peak mooring loads, while avoiding the costly overdesign or compromising the power production of the WEC. MMs play a vital role in the design process, where the design solution is usually obtained iteratively, since the loads on the lines depend on the characteristics of the lines themselves [202].

The current state of mooring design for a number of Danish WECs is assessed by Thomsen et al. [15], providing a good overview of the procedures and analyses involved in mooring design. Fitzgerald and Bergdahl [22] and Martinelli et al. [23] also detail many important aspects of mooring design for WECs. For example, Fitzgerald and Bergdahl [22] uses MMs to compare different alternatives for the design of the mooring cables of a point absorber WEC in 50-m water depth. The MM analysis compares the different mooring designs in terms of the:

- Overall weight and cost required to handle the baseline extreme loads

- Mechanical impedance of the mooring cable at the attachment point and its likely influence on the motion of the floater

- Seabed footprint and horizontal movement at the surface, due to steady or slowly varying loads, and its likely influence on array efficiency

- Deployment considerations, required bollard pull for anchor embedding, etc.

From the results of the analysis by Fitzgerald and Bergdahl [22], the authors conclude that the use of synthetic cables with higher elasticity has the potential to greatly reduce the overall weight of the system.

Discussion of the range of environmental inputs to be considered, when designing a WEC mooring system is given by Bergdahl [32]. An illustrative example is presented to show the procedure for designing a mooring system, using static, quasi-static and dynamic models in different stages of the design process. A quasi-static design loop is used to initially design the mooring, and is then followed by sophisticated dynamic simulations. Dynamic calculations may first be run in the frequency domain, to allow many cases to be run, from which a few critical cases should be run in the time domain. 
The procedure of initially using a static analysis to identify potential mooring designs, to be then further refined and optimised with high fidelity dynamic analysis, is also recommended by Fonesca et al. [202]. The static formulation is extremely fast, providing estimates in a few seconds, while the dynamic formulation, depending on the complexity of the excitation and system, can take hours to provide stable statistical results [202]. Likewise, Johanning et al. [20] recommend using a static analysis, within a preliminary design approach, to estimate the maximum tension and stresses on the WEC mooring components due to extreme environmental conditions, from which the initial dimensions of the material components can be identified for further analysis.

Monarcha and Fonesca [203] present a static analytical method for the preliminary design, of multiple line mooring systems, for floating offshore structures. The thesis by Wang [182], presents an evolutionary optimisation study on offshore mooring system design, detailing the use of MMs with numerical optimisation techniques to provide tools to aid in the design and optimisation of offshore mooring systems.

Table 5. Review of publications utilising mooring models for the design of a WEC mooring system.

\begin{tabular}{|c|c|c|c|}
\hline Ref. & WEC Type & Mooring System & Model \\
\hline [202] & Hinged barge (FLOW WEC) & Weathervaning spread M. & QS, Finite-Differences \\
\hline$[83]$ & 2 body heaving PA (SyncWave) & Multiple leg-3 point $\mathrm{M}$. & NL TD (Proteus-DS) \\
\hline [185] & Attenuator (OCEANTEC) & Multi-catenary spread M. & QS \& TD (OrcaFlex) \\
\hline [193] & Heaving PA & 3 cable spread $\mathrm{M}$. & Finite element (AQUA FE) \\
\hline [204] & PA & $\begin{array}{l}\text { Slack chain, with \& without } \\
\text { submerged floater buoy }\end{array}$ & QS \\
\hline [190] & 2 body heaving PA & $\begin{array}{l}4 \text { cable spread M. with } \\
\text { submerged floats }\end{array}$ & $\begin{array}{l}\text { NL TD lumped } \\
\text { mass (Proteus DS) }\end{array}$ \\
\hline$[43]$ & Large floating WECs & Slack chain, taut SPM \& SALM & QS \\
\hline [205] & $\begin{array}{c}\text { Combined wave \& wind } \\
\text { platform (Floating Power Plant) }\end{array}$ & Turret system with 3 lines & QS \\
\hline [206] & Heaving PA & Slack chain, floaters \& weights & QS \\
\hline$[22]$ & PA & $\begin{array}{l}\text { Catenary with/without buoys \& } \\
\text { clump weights, \& taut M. }\end{array}$ & $\begin{array}{l}\text { Static \& TD } \\
\text { (MODEX) }\end{array}$ \\
\hline [183] & $\begin{array}{l}\text { Combined wind \& wave } \\
\text { platform }(\mathrm{C}-\mathrm{HyP})\end{array}$ & 6 chain catenary lines & OrcaFlex \\
\hline [5] & $\begin{array}{l}\text { Overtopping WEC } \\
\text { (Wave Dragon) }\end{array}$ & $\begin{array}{l}5 \text { cable catenary to central } \\
\text { buoy connected to the WEC }\end{array}$ & SIMO/Riflex \\
\hline
\end{tabular}

\subsection{Fatigue Analysis}

Fatigue assessment of the mooring lines is crucial to ensure the integrity of the mooring system over its operational lifetime. A WEC experiences a multitude of different sea states (mild, moderate and severe) during its lifetime, and the fatigue assessment of the mooring system should be based on the aggregate of the load effects from the various sea states [137]. Using a quasi-static MM significantly underpredicts the mooring loads, especially for fatigue [89]; therefore, a dynamic model is required. For each sea state condition, a dynamic analysis is required to capture the stresses and loads on the system, encapsulating the HF system responses within a lengthy simulation duration, to ensure sufficient cycles for the LF responses are represented. Therefore, fatigue analysis for WEC mooring systems requires efficient modelling procedures. 
The fatigue life of a mooring line is assessed by the number of stress cycles the mooring line sustains before failure. There are a number of techniques used to perform the fatigue assessment, ranging from the more accurate but computationally costly cycle counting methods in the time domain, to the less accurate but computationally faster frequency domain methods, such as the simple summation, the combined spectrum and the dual narrow-band approaches. A detailed description of the different methods can be found in the Position Mooring standard DNV-OS-E301 [30] and in the thesis by Larsen [207], which provides an assessment and comparison of the different methods for fatigue analysis of mooring systems.

Low [137] and Low and Cheung [208] outline techniques and model requirements for analysing the fatigue of moorings and risers in floating production systems for offshore oil and gas, presenting a hybrid time/frequency domain method to address the requirement of efficient modelling. Christiansen et al. [153] use system identification techniques to train neural networks on a FEM MM output to allow efficient mooring line fatigue assessment. Thies et al. [209] present a method to analyse annual fatigue conditions from a limited number of experimental tanks tests, and from field measurements [210].

The thesis by Yang [211] focuses on the fatigue characteristics in mooring lines for WECs. The study compares various simulation procedures for the analysis of fatigue of WEC moorings, with the objective of recommending the type of simulation procedure that can be used to make reliable fatigue assessment of WEC mooring systems, for a reasonable computational effort. In Yang et al. [17], the authors compare using the coupled and uncoupled approaches and conclude that, although the uncoupled approach is believed to predict less accurately, the differences in terms of predicted fatigue damage is minor between the two approaches and, therefore, the uncoupled approach should be favoured due to the reduced amount of model preparation and computational effort required. However, in a later study by Yang et al. [166], the same authors conclude that the coupling effects are crucial for the fatigue damage analysis of the mooring line.

Snap loads have been seen to cause significant damage in a number of experiments and field tests $[35,209,212]$. Therefore, capturing the effect of snap loads is important for assessing the damage and fatigue to mooring lines. Palm et al. [86] highlight that using numerical methods which are not locally conservative, such as standard continuous finite element or centred finite difference methods, will have problems in correctly capturing snap loads. Palm et al. [86] present a finite element model, based on the discontinuous Galerkin method, that aims to capture the correct amplitude and duration of snap loads in mooring cables.

Table 6. Review of publications utilising mooring models for the fatigue of a WEC mooring system.

\begin{tabular}{llll}
\hline Ref. & WEC Type & Mooring System & Model \\
\hline$[17,166,211]$ & PA & 4 cable spread M. & $\begin{array}{l}\text { DNV Deep C \& MooDy, } \\
\text { Coupled \& Decoupled }\end{array}$ \\
\hline$[179]$ & $\begin{array}{l}\text { Combined floating wind turbine \& } \\
\text { axisymmetric 2 body WEC (STC) }\end{array}$ & $\begin{array}{l}3 \text { cable spread M. } \\
\text { with clump weights }\end{array}$ & SIMO \\
\hline
\end{tabular}

\subsection{Extreme Loads}

The occurrence of extreme, or peak, loads on WEC mooring systems must be carefully evaluated, to ensure a robust and efficient mooring design [213]. One of the main challenges, for a commercially successful WEC, is to ensure survivability in extreme conditions, at a reasonable cost [214]. Calculating the maximum tension in the mooring system requires a dynamic analysis; however, historically, quasi-static mooring analysis is used, and phenomena affecting the maximum line tension, that are neglected by this modelling procedure, were accounted for by an overall safety factor, with a typical value of three, for operational conditions, and two for survival conditions [101]. 
The thesis by Liu [134], focuses on the dynamic response analysis, and extreme value problems, of moored floating platforms. The usual process to estimate the extreme mooring line tensions is to perform many time domain simulations, which is computationally expensive. However, Liu [134] shows that only a few simulations, plus the extreme value theory presented therein, are required to predict the extreme mooring line tension. Liu calculates the expected extreme mooring cable tensions, due to WF excitations, using statistical methods, on nonlinear time domain simulations [215], and then extreme responses for moored floating platforms, under combined LF-WF excitation [216].

To enable efficient analysis of peak mooring loads, Low [136] presents a hybrid time domain-frequency domain approach for predicting extreme vessel motion, and line tension, for deep water floating systems. Muliawan et al. [175] examine reducing the computational requirements for extreme loads on a WEC mooring system, through parsimonious selection of input sea states to be simulated. The environmental conditions to be considered, for extreme load analysis of WEC mooring systems, are investigated experimentally, from field test measurements, in Harnois et al. [213].

Table 7. Review of publications utilising mooring models for the analysis of extreme loads on a WEC mooring system.

\begin{tabular}{llll}
\hline Ref. & WEC Type & Mooring System & Model \\
\hline$[174]$ & Wave Dragon & CALM & SIMO/Riflex \\
\hline$[27]$ & Hinged barge & 4 cable spread M. & ANSYS AQWA \\
\hline$[35]$ & Axisymmetric PA & 3 cable spread M. & OrcaFlex \\
\hline$[175,217]$ & 2 body heaving PA & 4 cable catenary & SIMO/RIFLEX \\
\hline \multirow{2}{*}[178]{} & Combined floating wind turbine \& & $\begin{array}{l}3 \text { cable spread M. } \\
\text { with clump weights }\end{array}$ & \multirow{2}{*}{ SIMO } \\
\hline$[218]$ & Largymmetric 2 body WE (STC) & 3-legged CALM, single leg SALM & QS \\
\hline$[184]$ & Water depths e.g., Weptos, Wave Dragon in intermediate & $\begin{array}{l}\text { 3 cable slack M. with buoys } \\
\text { \& clump weights }\end{array}$ & \multirow{2}{*}{ OrcaFlex } \\
\hline
\end{tabular}

\subsection{WEC simulation}

Numerical simulation is an essential tool in analysing and optimising the performance of a WEC. The mooring system will effect the WEC performance, adding nonlinear resistance and reactance to the WEC dynamics; therefore, a MM should be included into the WEC simulation to capture these effects. The effect of moorings on the motions of a point absorber WEC is studied in Fitzgerald and Bergdahl [123], where it is demonstrated that moorings can influence the absorbed wave energy and that the influence depends not just on the type of cable, but also on where it is attached to the device, and in what degree of freedom of the floater that power is extracted.

To properly account for the way in which the mooring system alters the impedance of the WEC dynamics, some form of dynamic analysis should be used [28]. The fidelity of the MM should match that of the rest of the WEC simulation; for example, if a frequency domain simulation of the WEC hydrodynamics and PTO system is being implemented, then the MM should be linear to allow a frequency domain implementation. 
Table 8. Review of publications utilising mooring models for WEC simulation.

\begin{tabular}{|c|c|c|c|}
\hline Refs. & WEC Type & Mooring System & Model \\
\hline [181] & $\begin{array}{l}\text { Multibody attenuator } \\
\text { (Pelamis) }\end{array}$ & $\begin{array}{l}3 \text { cable catenary } \\
\text { with submerged buoys }\end{array}$ & OrcaFlex \\
\hline [55] & PA reacting against sea floor & Tight M. line & L. TD \\
\hline [52] & PA reacting against sea floor & Tight M. line & NL TD \\
\hline [219] & $\begin{array}{l}\text { Pitching and surging PA } \\
\text { (PS Frog Mk5) }\end{array}$ & Undefined & L. RF \\
\hline [19] & $\begin{array}{l}\text { Pitching attenuator } \\
\text { (ISWEC) }\end{array}$ & $\begin{array}{l}\text { Chain cable with submerged } \\
\text { bouy \& clump weight }\end{array}$ & $\begin{array}{l}\text { QS, \& lumped } \\
\text { mass (MoorDyn) }\end{array}$ \\
\hline [220] & 2-body heaving PA & Slack M. & QS \\
\hline [53] & PA reacting against sea floor & Taut M. line & $\begin{array}{l}\text { NL RF TD, \& L. RF } \\
\text { FD }\end{array}$ \\
\hline [221] & OWC (BBDB) & Slack chain & Lumped mass \\
\hline [18] & 2 body heaving PA & 3 cable, semi taut, spread $\mathrm{M}$. & AQWA, SIMA \& OrcaFlex \\
\hline$[186,187]$ & 2 body heaving PA & Single tension leg & OrcaFlex \\
\hline [222] & $\begin{array}{l}\text { 3-body WEC } \\
\text { (SeaRay by CPT) }\end{array}$ & 3 point $\mathrm{M}$. system with 3 lines & $\begin{array}{l}\text { NL TD_Finite element } \\
\text { (LS-DYNA) }\end{array}$ \\
\hline [217] & 2 body heaving PA & 4 cable catenary & SIMO/RIFLEX \\
\hline [149] & Heaving PA & 3 cable catenary, \& 3 cable taut $\mathrm{M}$. & ANSYS AQWA \\
\hline [96] & PA & $1,2 \& 3$ cable catenary & QS \\
\hline [188] & OWC (OWEL) & 3 cable catenary & OrcaFlex \\
\hline [170] & 3-body WEC (Manta by CPT) & Undefined & OrcaFlex \\
\hline [223] & Floating oscillating flap & Slack \& taut M.s & L. RF term \\
\hline [126] & PA & 4 cable catenary, \& 4 cable taut $\mathrm{M}$. & L. RF term \\
\hline$[33]$ & PA & 4 cable catenary $\mathrm{M}$. & L. forces \\
\hline [224] & $\begin{array}{l}5 \text { DoF rectangular pontoon } \\
\text { (SurfPower), } \\
\& 2 \text { body heaving PA }\end{array}$ & $\begin{array}{l}4 \text { cables connected } \\
\text { to a single taut cable, } \\
\& \text { Slack moored }\end{array}$ & $\begin{array}{l}\text { Finite-element } \\
\text { (Protues-DS) }\end{array}$ \\
\hline [225] & 3-body oscillating flap device & Undefined & L. RF \\
\hline$[128]$ & OWC (BBDB) & $1 \& 2$ cable catenary & QS \\
\hline [85] & Heaving \& surging PA & Slack M. & NL TD—Finite differences \\
\hline [226] & 3-body hinged barge & Not specified & L. spring \& damper \\
\hline [227] & $\begin{array}{l}\text { Submerged horizontal } \\
\text { cylinder }\end{array}$ & $\begin{array}{l}\text { Vertical lines attached } \\
\text { to clump weight }\end{array}$ & L. RF \\
\hline
\end{tabular}

\subsection{WEC Control}

The effect of the mooring system on the WEC dynamics should be included when formulating the optimal energy maximisation control strategy. However, considering that mooring forces in the control formulation for WEC energy maximisation is relatively new, with none of the reviewed papers in Table 9 existing pre-2013. Model-based control solutions, where real-time computation is an absolute requirement, is typically fulfilled using simplified models. Including mooring effects into the WEC model would therefore require a very computationally efficient MM to fulfil the real-time computation requirement.

Apart from energy maximisation, one important objective for MMs in WEC control, not currently reported anywhere in the literature, is the minimisation of mooring fatigue or extreme loads, 
using control strategies. The objective of minimising mooring fatigue using control strategies is similar to the work of Ferri et al. [228] and Tom et al. [229], who investigate minimising structural fatigue of a WEC via control. Parmeggiani et al. [214] investigate using control strategies to reduce the peak mooring loads in extreme wave conditions, and presents a method which is able to reduce the extreme loads in the main mooring line by $20-30 \%$ in wave conditions over a 100 year return period; however, this is an exclusively experimental investigation and no MMs are used.

Table 9. Review of publications utilising mooring models for WEC control.

\begin{tabular}{llll}
\hline Ref. & WEC Type & M. System & Model \\
\hline$[230]$ & 2 body heaving PA (L10 WEC) & 3 cable taut M. & L. RF \\
{$[231]$} & 2 body heaving PA (L10 WEC) & 3 cable taut M. & L. \& NL RF \\
{$[232]$} & 2 body heaving PA (L10 WEC) & 8 cable taut M. & L. \& NL RF \\
{$[233]$} & 2 body heaving PA (L10 WEC) & 8 cable taut M. & NL RF \\
{$[234]$} & 2 body heaving PA (L10 WEC) & Single cable taut M. & L. RF \\
{$[54]$} & PA reacting against sea floor & Taut M. & NL RF \\
\hline
\end{tabular}

\subsection{Arrays}

The complexity of WEC mooring systems increases for the case of WEC arrays, with the number of degrees of freedom of the system increasing with the number of bodies and mooring lines within the array which, in turn, increases the complexity of the MM. Additionally, factors such as stricter restrictions on device excursions to maintain optimal spacing between devices, anchor sharing, and number of inter-body lines, add to the complexity of the analysis of mooring systems for WEC arrays.

Table 10. Review of publications utilising mooring models for WEC array analysis.

\begin{tabular}{|c|c|c|c|}
\hline Ref. & WEC Type & Mooring System & Model \\
\hline [235] & Heaving 2 body PAs & $\begin{array}{l}\text { Network of catenary lines with } \\
\text { surface buoys \& clump weights }\end{array}$ & $\begin{array}{l}\text { L. RF FD, } \\
\text { OrcaFlex for TD }\end{array}$ \\
\hline [236] & Array of 3 heaving PAs & $\begin{array}{l}\text { Spread M. from each WEC to sea floor, plus } \\
3 \text { inter-body lines to a central clump weight }\end{array}$ & $\begin{array}{l}\text { L. RF FD, } \\
\text { inter-body coupling }\end{array}$ \\
\hline [129] & Array of 3 heaving PAs & $\begin{array}{l}\text { Spread M. from each WEC to sea floor, plus } \\
3 \text { inter-body lines to a central clump weight }\end{array}$ & $\begin{array}{l}\text { L. RF FD, } \\
\text { inter-body coupling }\end{array}$ \\
\hline [237] & Array of 3 heaving PAs & $\begin{array}{l}\text { Spread M. from each WEC to sea floor, plus } \\
3 \text { inter-body lines to a central clump weight }\end{array}$ & QS \\
\hline [238] & $\begin{array}{l}\text { OWC (BBDB) } \\
5 \text { DoF pontoon (SurfPower) } \\
2 \text { body heaving PA }\end{array}$ & $\begin{array}{l}3 \text { cable spread catenary } \\
4 \text { cables connected to a single taut cable } \\
\text { Slack moored }\end{array}$ & $\begin{array}{l}\text { Finite-element } \\
\text { (Protues-DS) }\end{array}$ \\
\hline [38] & Array of 6 PAs & 3 cable catenary & DeepC/SIMA/Riflex \\
\hline [24] & Array of 9 FO3 WECs & $\begin{array}{l}\text { Horizontal M. lines linking WECs } \\
\text { together \& to surface buoys connected } \\
\text { by vertical lines to sea floor }\end{array}$ & DeepC \& MIMOSA \\
\hline [239] & Array of 3 OWCs & Interbody cables \& vertical cables to sea floor & Linear spring \\
\hline
\end{tabular}

Integrated mooring systems may offer cost reductions, compared to individual moorings for each WEC in the array. This was investigated by Gao and Moan [24], who analysed the WEC motions and mooring tensions for an array compared with the motions and tensions for a single WEC in operational, and survival, conditions. Large mooring line tension in horizontal inter-body mooring lines were observed when the dynamic motions of two adjacent WECs were driven by waves with a phase difference of 180 degrees, resulting in a very high demand on mooring line capacity. In this 
case, the individual mooring system would prove more feasible than the integrated mooring system, however, by increasing the line lengths and by using clump weights, the tensions of the inter-body lines in the integrated mooring system could have been reduced.

\section{Considerations}

The review in this paper has presented many different modelling options and methods for WEC mooring systems, with varying levels of complexity and capabilities. Section 7.1 discusses the factors which need consideration when selecting the appropriate model for WEC mooring systems. Issues relating to the coupling and interfacing of MMs with other subsystem models of the overall WEC system are then considered in Section 7.2. Lastly in Section 7.3, the broad frequency range over which different phenomena which influence the mooring system, and how MMs best handle these varying time scales, is considered.

\subsection{Model Selection}

Selecting the appropriate MM is dependent on a number of factors, such as the:

- Type of application the MM is being applied to

- Operating principle of the WEC

- WEC location

The range of different applications was reviewed in Section 6 and, in general, there is no "one size fits all" MM best suited for every type of application; rather, the model selection requires an ideal balance between computational cost and accuracy of results, for the particular analysis being performed. For example, in the analysis of the FO3 WEC, Gao and Moan [24] show that a frequency domain method can accurately predict the motion and tension responses in an operational condition, while it will underestimate the responses in a survival condition.

When evaluating the power production and efficiency of WECs, the recent report by the International Ship and Offshore Structures Congress Committee on Offshore Renewable Energy recommends that time-domain modelling methods, including nonlinear mooring forces, are used [240]. However, simpler models can often be used in the initial design and anaylsis stages, and then more detailed models are gradually introduced, as the design and analysis becomes more refined [241]. For instance, Fitzgerald and Bergdahl [22] use a static analysis for cable sizing and mooring layout design/footprint for arrays, and then use a dynamic analysis for extreme loads and the influence of the mooring system on the WEC performance.

The operating principle of the WEC, and whether an active, passive or reactive mooring system is required, will impact the choice of MM. For example, when analysing the mooring system design for large WECs with a passive mooring system, Thomsen et al. [43] show that the use of quasi-static MMs is justifiable; however, Johanning et al. [10] show that responses can not be sensibly modelled in a quasi-static manner, once a semi-taut condition is reached, or once the fairlead oscillating frequency takes values above the natural line frequency, which may be the case for a point absorber with a reactive mooring system. In addition to the operating principle, the location of the WEC will also influence the appropriate MM selection. For example, quasi-static models are not well suited for deep water (>100 m) applications [57]. In the analysis of a slack moored spar in a water depth of $1018 \mathrm{~m}$ [242] shows that the mooring line tension, in the WF range, predicted by the coupled dynamic approach, can be eight times as great as the corresponding prediction by the quasistatic approach.

\subsection{Interfacing and Coupling with Other Models}

The differences between coupled and uncoupled MMs were discussed in Section 4.3.4. The implementation of the coupling between the MM and the rest of the WEC system requires some consideration. The model of the complete WEC system may comprise a number of subsystems, with separate models for the hydrodynamics, PTO system and the WEC hull dynamics. Each of these 
models may have different time steps and require information from the output of other subsystem models. For instance, Palm et al. [243] couple a finite element MM with a CFD simulation of a floating WEC, where the time step of the CFD simulation was $\Delta t_{C F D} \propto 10^{-2} \mathrm{~s}$, but the time step required by the MM was on the order of $\Delta t_{M M} \propto 10^{-4} \mathrm{~s}$. The computational time would be significantly increased, and impractical, if the CFD model was limited to the time step restriction of the MM; therefore, a sub-stepping scheme was implemented in the MM to handle the different time scales of the two problems.

The parallel architecture of multiprocessor computers may be leveraged to reduce the overall computation time for a complete WEC system, by solving the models of the different subsystems on different processors in parallel. Jacob et al. [244] and Rodrigues et al. [119] present the implementation of domain decomposition strategies where a "master-slave" scheme is utilised to solve the hull equations in the "master" processor and the equations of each mooring line are solved in the "slave" processors. The domain decomposition strategy also allows the finite element mesh of each mooring line to be partitioned amongst processors.

\subsection{Low Frequency vs. High Frequency}

One of the challenging aspects, in modelling WEC mooring systems, is the very broad frequency range of environmental inputs and mooring system responses. The time scales over which relevant physical phenomena in the mooring system occur cover:

- Static loading, which varies on the very LF time scale of the tidal influences

- LF horizontal second order wave drift motions of the WEC

- WF motion of the WEC and the water

- HF snap loads propagating through, and VIVs acting on, the line

Since these effects occur at different frequencies, one modelling approach may be to treat each of them separately, in order to make the modelling tractable [245]. However, in reality, the mooring dynamics at different frequencies are, in fact, coupled and this coupling should be taken into account for accurate modelling of the mooring system. For instance, superimposing WF motions with LF motion leads to an amplification in mooring line damping, caused by the quadratic dependence of the drag force on the relative velocity between the line and fluid [51]. Moreover, there is a parametric influence of the LF motion on the WF motion, because the slow variation of the mooring line shape influences the dynamic mooring line behaviour in the WF range [85].

Coupling LF models with WF models is addressed by Low [136] and Low and Langley $[130,138]$. Low and Langley [130] specifically highlight two different types of couplings, namely, Type 1 and Type 2 (introduced in Section 4.3.4), where Type 1 coupling refers to the WEC-mooring coupling and Type 2 coupling refers to the coupling between the system response at different frequencies. Low and Langley [130] propose that the term "fully coupled analysis" should be strictly reserved for the case when both kinds of coupling are rigorously captured in an analysis. Thus, fully coupled time domain simulations are exceedingly expensive in terms of computational time, since the time step must be small enough to resolve the WF dynamic effects while, at the same time, the total duration of a simulation must include enough LF cycles. Efficiency is achieved by accounting for some, or all, of the coupling effects in an approximate manner and, inevitably, certain inherent assumptions and simplifications are made. For example, Liu and Bergdahl $[134,216]$ investigate simple, reliable and physically sound techniques to estimate the combination of LF and WF extreme responses.

The mooring dynamics of shallow water WECs are influenced, on the very LF time scale, by the slowly varying water depth, due to the effect of changing tides. For example, Murphy et al. [149] investigate the effect of tidal range on WEC mooring systems, finding that the mooring forces increase with increasing tidal height, and conclude that tidal range may be a critically important parameter to consider, when designing WEC mooring systems. Harnois et al. [213] show that occurrences of peak mooring loads seem to be higher for low tide conditions, which possibly could be explained by the fact 
that the pre-tension in the mooring system is reduced for low tide, consequently leading to snatch load occurrence. Based on the results of Harnois et al. [213], it is recommend that several tidal elevations should be considered for WEC mooring design, with an emphasis on low tide conditions.

An ultra-LF time varying effect to consider is the changes to the mechanical properties, i.e., stiffness and damping, of certain mooring lines as they age, as shown by Weller et al. [77]. Additionally, effects such as marine growth and biofouling will also very slowly change the mechanical properties of the mooring lines, which is analysed by Yang et al. [246], where the biofouling is modelled as an increase in the mass and drag coefficients of the mooring lines, following the recommended procedure defined in DNV OS-E301 [30].

\section{Conclusions}

Mathematical modelling for WEC mooring systems borrows many established techniques from other offshore engineering fields, due to the common need to design, analyse and optimise moorings for floating structures. Various modelling techniques of increasing complexity and fidelity are available, with the most accurate model types being very computationally costly compared to their simpler counterparts. The type of model will depend on the operating principles of the WEC, the type of mooring system used, and the analysis application.

The full range of effects to be captured by MMs spans many time scales, covering very HF effects such as snap loads and dynamic tensions, WF oscillations, LF drift motions, and very LF tidal variations. This requires the simulations to have very small time steps, to capture the HF effects, but long simulation durations to capture the LF effects. Additionally, the WEC and mooring system models should be subjected to a range of sea states and environmental conditions, which need to be analysed by separate simulations. Therefore, pragmatic choices need to be made regarding the type of model to use and which inputs to consider, to achieve the best balance between computational requirements and accuracy of results.

In this review, the literature reporting the usage of MMs is collated and separated into the application areas of design, fatigue analysis, extreme loads, WEC simulation, WEC control and array analysis. Fatigue and extreme load analysis are seen to require the highest fidelity MMs, able to capture the dynamic tensions and effects throughout the mooring line. WEC simulation and control applications mainly require the effect of the mooring system on the WEC dynamics, i.e., the mechanical impedance of the mooring system, which generally allows more simplified MMs to be utilised. Simpler models are useful for the real time computational requirements of WEC control, and for the long simulation durations and numerous sea state simulations required for power production assessments from WEC simulations. Mooring design and array layout optimisation applications are seen to utilise simple models, initially, and then increase the model fidelity, as the design and analysis becomes more refined.

Acknowledgments: This paper is based upon work supported by Science Foundation Ireland under Grant No. 13/IA/1886.

Author Contributions: J.D. and J.V.R. conceived the review and designed its outline; J.D. performed the review and wrote the paper; J.V.R. edited and revised the paper.

Conflicts of Interest: The authors declare no conflict of interest.

\section{References}

1. Weber, J. WEC Technology Readiness and Performance Matrix-Finding the best research technology development trajectory. In Proceedings of the 4th International Conference on Ocean Energy, Dublin, Ireland, 17-19 October 2012.

2. Folley, M. (Ed.) Numerical Modelling of Wave Energy Converters—State of the Art Techniques for Single Devices and Arrays; Elsevier: London, UK, 2016.

3. Penalba, M.; Ringwood, J.V. A Review of Wave-to-Wire Models for Wave Energy Converters. Energies 2016, 9,506 . 
4. Harris, R.E.; Johanning, L.; Wolfram, J. Mooring systems for wave energy converters: A review of design issues and choices. In Proceedings of the 3rd International Conference on Marine Renewable Energy, Blyth, UK, 7-9 July 2004.

5. Friis-Madsen, E.; Sørensen, H.; Parmeggiani, S. The development of a 1.5 MW Wave Dragon North Sea Demonstrator. In Proceedings of the 4th International Conference on Ocean Energy, Dublin, Ireland, 17-19 October 2012.

6. Vickers, A.; Johanning, L. Comparison of damping properties for three different mooring. In Proceedings of the 8th European Wave and Tidal Energy Conference, Uppsala, Sweden, 7-10 September 2009.

7. Bergdahl, L.; Palm, J.; Eskilsson, C.; Lindahl, J. Dynamically Scaled Model Experiment of a Mooring Cable. J. Mar. Sci. Eng. 2016, 4, 5.

8. Webster, W.C. Mooring-induced damping. Ocean Eng. 1995, 22, 571-591.

9. Kitney, N.; Brown, D.T. Experimental investigation of mooring line loading using large and small-scale models. J. Offshore Mech. Arctic Eng. 2001, 123, 1-9.

10. Johanning, L.; Smith, G.H.; Wolfram, J. Measurements of static and dynamic mooring line damping and their importance for floating WEC devices. Ocean Eng. 2007, 34, 1918-1934.

11. Johanning, L.; Smith, G. Improved measurement technologies for floating wave energy converter (WEC) mooring arrangements. Underw. Technol. 2008, 27, 175-184.

12. Brown, D.; Mavrakos, S. Comparative study on mooring line dynamic loading. Mar. Struct. 1999, 12, $131-151$.

13. Thomas, D.O. A Numerical Investigation of Time Integration Schemes Applied to The Dynamic Solution of Mooring Lines. Ph.D. Thesis, The University of Newcastle upon Tyne, Newcastle upon Tyne, UK, 1993.

14. Chatjigeorgiou, I.; Mavrakos, S. Comparison of numerical methods for predicting the dynamic behavior of mooring lines. In Proceedings of the the Ninth International Offshore and Polar Engineering Conference, Brest, France, 30 May-4 June 1999

15. Thomsen, J.B.; Ferri, F.; Kofoed, J.P. Assessment of Current State of Mooring Design in the Danish Wave Energy Sector. In Proceedings of the 11th European Wave and Tidal Energy Conference, Nantes, France, 6-11 September 2015.

16. Harnois, V.; Weller, S.D.; Johanning, L.; Thies, P.R.; Le Boulluec, M.; Le Roux, D.; Soule, V.; Ohana, J. Numerical model validation for mooring systems: Method and application for wave energy converters. Renew. Energy 2015, 75, 869-887.

17. Yang, S.H.; Ringsberg, J.W.; Johnson, E. Analysis of Mooring Lines for Wave Energy Converters: A Comparison of De-Coupled and Coupled Simulation Procedures. In Proceedings of the ASME 2014 33rd International Conference on Ocean, Offshore and Arctic Engineering, San Francisco, CA, USA, 8-13 June 2014. p. V04AT02A034.

18. Bhinder, M.A.; Karimirad, M.; Weller, S.; Debruyne, Y.; Guérinel, M.; Sheng, W. Modelling mooring line non-linearities (material and geometric effects) for a wave energy converter using AQWA, SIMA and Orcaflex. In Proceedings of the 11th European Wave and Tidal Energy Conference, Nantes, France, 6-11 September 2015.

19. Vissio, G.; Passione, B.; Hall, M.; Raffero, M. Expanding ISWEC Modelling with a Lumped-Mass Mooring Line Model. In Proceedings of the European Wave and Tidal Energy Conference, Nantes, France, 6-11 September 2015.

20. Johanning, L.; Smith, G.H.; Wolfram, J. Towards design standards for WEC moorings. In Proceedings of the 6th European Wave and Tidal Energy Conference, Glasgow, UK, 29 August-2 September 2005.

21. Johanning, L.; Smith, G.; Wolfram, J. Mooring design approach for wave energy converters. Proc. Instit. Mech. Eng. Part M J. Eng. Marit. Environ. 2006, 220, 159-174.

22. Fitzgerald, J.; Bergdahl, L. Considering mooring cables for offshore wave energy converters. In Proceedings of the 7th European Wave Tidal Energy Conference, Porto, Portugal, 11-13 September 2007.

23. Martinelli, L.; Ruol, P.; Cortellazzo, G. On mooring design of wave energy converters: The Seabreath application. Coast. Eng. Proc. 2012, 1, 3.

24. Gao, Z.; Moan, T. Mooring system analysis of multiple wave energy converters in a farm configuration. In Proceedings of the 8th European Wave and Tidal Energy Conference, Uppsala, Sweden, 7-10 September 2009; pp. 509-518. 
25. Karimirad, M.; Koushan, K.; Weller, S.; Hardwick, J.; Johanning, L. Applicability of offshore mooring and foundation technologies for marine renewable energy (MRE) device arrays. In Proceedings of the International Conference on Renewable Energies Offshore, Lisbon, Portugal, 24-26 November 2014.

26. Sound and Sea Technology. Advanced Anchoring and Mooring Study; Technical Report; Oregon Wave Energy Trust, Portland, OR, USA, 30 November 2009.

27. Angelelli, E.; Zanuttigh, B.; Martinelli, L.; Ferri, F. Physical and numerical modelling of mooring forces and displacements of a Wave Activated Body Energy Converter. In Proceedings of the ASME 2014 33rd International Conference on Ocean, Offshore and Arctic Engineering, San Francisco, CA, USA, 8-13 June 2014; p. V09AT09A044.

28. Paredes, G.M.; Bergdahl, L.; Palm, J.; Eskilsson, C.; Pinto, F.T. Station keeping design for floating wave energy devices compared to floating offshore oil and gas platforms. In Proceedings of the 10th European Wave and Tidal Energy Conference, Aalborg, Denmark, 2-5 September 2013.

29. Vickers, A. Improve the Understanding of Uncertainties in Numerical Analysis of Moored Floating Wave Energy Converters. Ph.D. Thesis, University of Exeter, Exeter, UK, 2012.

30. Det Norske Veritas. Offshore Standard_Position Mooring; DNV OS-E301; Det Norske Veritas: Høvik, Norway, 2013.

31. Harnois, V.; Johanning, L.; Thies, P.R. Wave conditions inducing extreme mooring loads on a dynamically responding moored structure. In Proceedings of the 10th European Wave and Tidal Energy Conference, Aalborg, Denmark, 2-5 September 2013.

32. Bergdahl, L. Mooring Design for WECs. In Handbook on Ocean Wave Energy; Springer: Cham, Switzerland, 2016; pp. 159-202.

33. Bachynski, E.E.; Young, Y.L.; Yeung, R.W. Analysis and optimization of a tethered wave energy converter in irregular waves. Renew. Energy 2012, 48, 133-145.

34. Fonseca, N.; Pascoal, R.; Marinho, J.; Morais, T. Analysis of wave drift forces on a floating wave energy converter. In Proceedings of the ASME 2008 27th International Conference on Offshore Mechanics and Arctic Engineering, Estoril, Portugal, 15-20 June 2008; pp. 831-839.

35. Harnois, V. Analysis of Highly Dynamic Mooring Systems: Peak Mooring Loads in Realistic Sea Conditions. Ph.D. Thesis, University of Exeter, Exeter, UK, 2014.

36. Hong, D.; Hong, S.; Hong, S. Numerical study on the reverse drift force of floating BBDB wave energy absorbers. Ocean Eng. 2004, 31, 1257-1294.

37. Retzler, C. Measurements of the slow drift dynamics of a model Pelamis wave energy converter. Renew. Energy 2006, 31, 257-269.

38. Herduin, M.; Gaudin, C.; O'Loughlin, C. Multi-Directional Loading Cases on Shared Anchors for an Array of Wave Energy Converters. In Proceedings of the 3rd Asian Wave and Tidal Energy Conference, Singapore, 24-28 October 2016.

39. Martinelli, L.; Lamberti, A.; Ruol, P.; Ricci, P.; Kirrane, P.; Fenton, C.; Johanning, L. Power Umbilical for Ocean Renewable Energy Systems-Feasibility and Dynamic Response Analysis. In Proceedings of the 3rd International Conference on Ocean Energy, Bilbao, Spain, 6-8 October 2010.

40. Yang, S.H.; Ringsberg, J.; Johnson, E. Parametric study of the mechanical characteristics of power cables under dynamic motions. In Proceedings of the 11th European Wave and Tidal Energy Conference, Nantes, France, 6-11 September 2015.

41. Thies, P.R.; Johanning, L.; Smith, G.H. Assessing mechanical loading regimes and fatigue life of marine power cables in marine energy applications. Proc. Insti. Mech. Eng. Part O J. Risk Reliab. 2012, 226, 18-32.

42. Huang, M.; Aggidis, G.A. Developments, expectations of wave energy converters and mooring anchors in the UK. J. Ocean Univ. China 2008, 7, 10-16.

43. Thomsen, J.B.; Kofoed, J.P.; Delaney, M.; Banfield, S.; Initial Assessment of Mooring Solutions for Floating Wave Energy Converters. In Proceedings of the 26th International Ocean and Polar Engineering Conference, Rhodes, Greece, 26 June-1 July 2016.

44. Walton, T.S.; Polachek, H. Calculation of transient motion of submerged cables. Math. Comput. 1960, 14, $27-46$.

45. Polachek, H.; Walton, T.; Mejia, R.; Dawson, C. Transient motion of an elastic cable immersed in a fluid. Math. Comput. 1963, 17, 60-63. 
46. Harleman, D.R.; Shapiro, W.C. The dynamics of a submerged moored sphere in oscillatory waves. Coast. Eng. Proc. 1960, 1, 41.

47. Chatjigeorgiou, I.; Mavrakos, S. Assessment of bottom-cable interaction effects on mooring line dynamics. In Proceedings of the 17th International Conference on Offshore Mechanics and Arctic Engineering, Lisbon, Portugal, 5-6 July 1998.

48. Garza Rios, L.O.; Bernitsas, M.M.; Nishimoto, K. Catenary Mooring Lines with Nonlinear Drag and Touchdown; University of Michigan/Industry Consortium in Offshore Engineering: Ann Arbor, MI, USA, 1997.

49. Jonkman, J.; Buhl, M. Development and verification of a fully coupled simulator for offshore wind turbines. In Proceedings of the 45th AIAA Aerospace Sciences Meeting and Exhibit, Reno, NV, USA, 8-11 January 2007; p. 212.

50. Det Norske Veritas. Offshore Standard-Global Performance Analysis of Deepwater Floating Structures; Technical Report, DNV-RP-F205; Det Norske Veritas: Høvik, Norway, 2010.

51. Brown, D.; Lyons, G.; Ln, H. Advances in mooring line damping. Underw. Technol. 1995, 21, 5-11.

52. Mavrakos, S.A.; Katsaounis, G.M.; Apostolidis, M.S. Effect of floaters' geometry on the performance characteristics of tightly moored wave energy converters. In Proceedings of the ASME 2009 28th International Conference on Ocean, Offshore and Arctic Engineering, Honolulu, HI, USA, 31 May-5 June 2009; pp. 1145-1152.

53. Vicente, P.C.; Falcão, A.F.; Justino, P.A. Nonlinear dynamics of a tightly moored point-absorber wave energy converter. Ocean Eng. 2013, 59, 20-36.

54. Jama, M.; Wahyudie, A.; Assi, A.; Noura, H. An intelligent fuzzy logic controller for maximum power capture of point absorbers. Energies 2014, 7, 4033-4053.

55. Spanos, P.D.; Arena, F.; Richichi, A.; Malara, G. Efficient Dynamic Analysis of a Nonlinear Wave Energy Harvester Model. J. Offshore Mech. Arctic Eng. 2016, 138, 041901.

56. Mavrakos, S.; Papazoglou, V.; Triantafyllou, M.; Hatjigeorgiou, J. Deep water mooring dynamics. Mar. Struct. 1996, 9, 181-209.

57. Mavrakos, S.; Chatjigeorgiou, J. Dynamic behaviour of deep water mooring lines with submerged buoys. Comput. Struct. 1997, 64, 819-835.

58. Yuan, Z.M.; Incecik, A.; Ji, C. Numerical study on a hybrid mooring system with clump weights and buoys. Ocean Eng. 2014, 88, 1-11.

59. Tahar, A.; Kim, M. Coupled-dynamic analysis of floating structures with polyester mooring lines. Ocean Eng. 2008, 35, 1676-1685.

60. Flory, J.F.; Banfield, S.P.; Petruska, D.J.; Defining, measuring, and calculating the properties of fiber rope deepwater mooring lines. In Proceedings of the Offshore Technology Conference, Houston, TX, USA, 3-6 May 2004.

61. ANSYS, Inc. AQWA-Theory Manual; 15.0 ed.; ANSYS, Inc.: Canonsburg, PA, USA, 2013.

62. Tsukrov, I.; Eroshkin, O.; Paul, W.; Celikkol, B. Numerical modeling of nonlinear elastic components of mooring systems. IEEE J. Ocean. Eng. 2005, 30, 37-46.

63. Jain, R. A simple method of calculating the equivalent stiffnesses in mooring cables. Appl. Ocean Res. 1980, 2, 139-142.

64. Papazoglou, V.; Mavrakos, S.; Triantafyllou, M. Non-linear cable response and model testing in water. J. Sound Vib. 1990, 140, 103-115.

65. Gobat, J.I. The Dynamics of Geometrically Compliant Mooring Systems. Ph.D. Thesis, Massachusetts Institute of Technology and Woods Hole Oceanographic Institution, Cambridge, MA, USA, 2000.

66. Morison, J.; Johnson, J.; Schaaf, S.; The force exerted by surface waves on piles. J. Pet. Technol. 1950, 2, 149-154.

67. Johanning, L.; Smith, G.H.; Wolfram, J. Interaction between mooring line damping and response frequency as a result of stiffness alteration in surge. In Proceedings of the 25th International Conference on Offshore Mechanics and Arctic Engineering, Hamburg, Germany, 4-9 June 2006; pp. 403-412.

68. Raaijmakers, R. The Influence of Mooring Lines on the Damping of Low Frequency Motions of Moored Offshore Structures. Ph.D. Thesis, Delft University of Technology, Delft, The Netherlands, 1995.

69. Huse, E. New developments in prediction of mooring system damping. In Proceedings of the Offshore Technology Conference, Houston, TX, USA, 6-9 May 1991. 
70. Huse, E. Influence of mooring line damping upon rig motions. In Proceedings of the Offshore Technology Conference, Houston, TX, USA, 5-8 May 1986.

71. Liu, Y.; Bergdahl, L. Improvements on Huses s model for estimating mooring cable induced damping. In Proceedings of the ASME 17th International Conference on Offshore Mechanics and Arctic Engineering, Lisbon, Portugal, 5-6 July 1998.

72. Bauduin, C.; Naciri, M. A contribution on quasi-static mooring line damping. J. Offshore Mech. Arctic Eng. 2000, 122, 125-133.

73. Lie, H.; Gao, Z.; Moan, T. Mooring line damping estimation by a simplified dynamic model. In Proceedings of the ASME 2007 26th International Conference on Offshore Mechanics and Arctic Engineering, San Diego, CA, USA, 10-15 June 2007; pp. 197-204.

74. Liu, Y.; Bergdahl, L. Influence of current and seabed friction on mooring cable response: Comparison between time-domain and frequency-domain analysis. Eng. Struct. 1997, 19, 945-953.

75. Xu, Z.; Huang, S. Numerical investigation of mooring line damping and the drag coefficients of studless chain links. J. Mar. Sci. Appl. 2014, 13, 76-84.

76. Weller, S.; Davies, P.; Vickers, A.; Johanning, L. Synthetic rope responses in the context of load history: Operational performance. Ocean Eng. 2014, 83, 111-124.

77. Weller, S.; Davies, P.; Vickers, A.; Johanning, L. Synthetic rope responses in the context of load history: The influence of aging. Ocean Eng. 2015, 96, 192-204.

78. Srinil, N.; Wiercigroch, M.; O'Brien, P. Reduced-order modelling of vortex-induced vibration of catenary riser. Ocean Eng. 2009, 36, 1404-1414.

79. Vandiver, J. Dimensionless parameters important to the prediction of vortex-induced vibration of long, flexible cylinders in ocean currents. J. Fluids Struct. 1993, 7, 423-455.

80. Gobat, J.; Grosenbaugh, M. Time-domain numerical simulation of ocean cable structures. Ocean Eng. 2006, 33, 1373-1400.

81. Low, Y.; Langley, R. Time and frequency domain coupled analysis of deepwater floating production systems. Appl. Ocean Res. 2006, 28, 371-385.

82. Pesce, C.P.; Martins, C.D.A.; da Silveira, L.M. Riser-soil interaction: Local dynamics at TDP and a discussion on the eigenvalue and the VIV problems. J. Offshore Mech. Arctic Eng. 2006, 128, 39-55.

83. Beatty, S.; Hiles, C.; Nicoll, R.S.; Adamson, J.E.; Buckham, B.J. Design synthesis of a wave energy converter. In Proceedings of the ASME 2009 28th International Conference on Ocean, Offshore and Arctic Engineering, Honolulu, HI, USA, 31 May-5 June 2009; pp. 891-900.

84. Wang, L.Z.; Guo, Z.; Yuan, F. Quasi-static three-dimensional analysis of suction anchor mooring system. Ocean Eng. 2010, 37, 1127-1138.

85. Cerveira, F.; Fonseca, N.; Pascoal, R. Mooring system influence on the efficiency of wave energy converters. Int. J. Mar. Energy 2013, 3, 65-81.

86. Palm, J.; Eskilsson, C.; Bergdahl, L. Mooring cable simulations with snap load capturing for wave energy applications. In Proceedings of the 2nd International Conference on Renewable Energies Offshore, Lisbon, Portugal, 24-28 October 2016.

87. Hann, M.; Greaves, D.; Raby, A. Snatch loading of a single taut moored floating wave energy converter due to focussed wave groups. Ocean Eng. 2015, 96, 258-271.

88. Vassalos, D.; Huang, S. Dynamics of small-sagged taut-slack marine cables. Comput. Struct. 1996, 58, 557-562.

89. Hall, M.; Goupee, A. Validation of a lumped-mass mooring line model with DeepCwind semisubmersible model test data. Ocean Eng. 2015, 104, 590-603.

90. Hall, M.; Buckham, B.; Crawford, C. Evaluating the importance of mooring line model fidelity in floating offshore wind turbine simulations. Wind Energy 2014, 17, 1835-1853.

91. Orcina. OrcaFlex-Documentation, 10.1b Edition. 2016. Available online: https://www.orcina.com/ SoftwareProducts/OrcaFlex/Documentation/ (accessed on 1 January 2017).

92. Oppenheim, B.; Wilson, P. Static 2-D solution of a mooring line of arbitary composition in the vertical and horizontal operating modes. Int. Shipbuild. Prog. 1982, 29, 142-153.

93. Smith, R.J.; MacFarlane, C.J. Statics of a three component mooring line. Ocean Eng. 2001, 28, 899-914.

94. Chai, Y.; Varyani, K.; Barltrop, N. Semi-analytical quasi-static formulation for three-dimensional partially grounded mooring system problems. Ocean Eng. 2002, 29, 627-649. 
95. Masciola, M.; Jonkman, J.; Robertson, A. Implementation of a Multisegmented, Quasi-Static Cable Model. In Proceedings of the 23rd International Offshore and Polar Engineering Conference, Anchorage, AK, USA, 30 June-5 July 2013.

96. Nava, V.; Rajic, M.; Soares, C.G. Effects of the mooring line configuration on the dynamics of a point absorber. In Proceedings of the ASME 2013 32nd International Conference on Ocean, Offshore and Arctic Engineering, Nantes, France, 9-14 June 2013; p. V008T09A071.

97. Yang, M.; Teng, B.; Ning, D.; Shi, Z. Coupled dynamic analysis for wave interaction with a truss spar and its mooring line/riser system in time domain. Ocean Eng. 2012, 39, 72-87.

98. Triantafyllou, M. Cable Mechanics With Marine Applications; Lecture Notes; Department of Ocean Engineering, Massachusetts Institute of Technology: Cambridge, MA, USA, 1990.

99. Aranha, J.; Pinto, M. Dynamic tension in risers and mooring lines: An algebraic approximation for harmonic excitation. Appl. Ocean Res. 2001, 23, 63-81.

100. Masciola, M.; Jonkman, J.; Robertson, A. Extending the capabilities of the mooring analysis program: A survey of dynamic mooring line theories for integration into FAST. In Proceedings of the ASME 2014 33rd International Conference on Ocean, Offshore and Arctic Engineering, San Francisco, CA, USA, 8-13 June 2014; p. V09AT09A032.

101. Van den Boom, H. Dynamic behaviour of mooring lines. In Proceedings of the BOSS Conference, Delft, The Netherlands, 1-5 July 1985.

102. Khan, N.U.; Ansari, K.A. On the dynamics of a multicomponent mooring line. Comput. Struct. 1986, 22, 311-334.

103. Chai, Y.; Varyani, K.; Barltrop, N. Three-dimensional Lump-Mass formulation of a catenary riser with bending, torsion and irregular seabed interaction effect. Ocean Eng. 2002, 29, 1503-1525.

104. Buckham, B.J. Dynamics modelling of low-tension tethers for submerged remotely operated vehicles. Ph.D. Thesis, University of Victoria, Victoria, BC, Canada, 2003.

105. Ablow, C.; Schechter, S. Numerical simulation of undersea cable dynamics. Ocean Eng. 1983, 10, $443-457$.

106. Howell, C.T. Investigation of the Dynamics of Low-Tension Cables. Ph.D. Thesis, Woods Hole Oceanographic Institution, Massachusetts Institute of Technology, Cambridge, MA, USA, 1992.

107. Chatjigeorgiou, I.K. A finite differences formulation for the linear and nonlinear dynamics of 2D catenary risers. Ocean Eng. 2008, 35, 616-636.

108. Aamo, O.M.; Fossen, T.I. Finite element modelling of mooring lines. Math. Comput. Simul. 2000, 53, 415-422.

109. Aamo, O.; Fossen, T. Finite element modelling of moored vessels. Math. Comput. Model. Dyn. Syst. 2001, 7,47-75.

110. Palm, J.; Paredes, G.M.; Eskilsson, C.; Pinto, F.T.; Bergdahl, L. Simulation of mooring cable dynamics using a discontinuous Galerkin method. In Proceedings of the 5th International Conference on Computational Methods in Marine Engineering, Hamburg, Germany, 29-31 May 2013.

111. Montano, A.; Restelli, M.; Sacco, R. Numerical simulation of tethered buoy dynamics using mixed finite elements. Comput. Methods Appl. Mech. Eng. 2007, 196, 4117-4129.

112. Palm, J. Developing Computational Methods for Moored Floating Wave Energy Devices. Licentiate Thesis, Chalmers University of Technology, Gothenburg, Sweden, 2014.

113. Winget, J.; Huston, R. Cable dynamics-A finite segment approach. Comput. Struct. 1976, 6, 475-480.

114. Kamman, J.W.; Huston, R.L. Modelling of submerged cable dynamics. Comput. Struct. 1985, 20, $623-629$.

115. Nichol, T.; DuBuque, G.; Fabien, B.; Dynamic Modelling of Compliant-Moored Submerged Systems with Applications to Marine Energy Converters. In Proceedings of the 2nd Marine Energy Technology Symposium, Seattle, WA, USA, 15-17 April 2014.

116. Garrett, D. Coupled analysis of floating production systems. Ocean Eng. 2005, 32, 802-816.

117. Filipich, C.; Rosales, M. Dynamic Analysis of plane mooring chains of inextensible links. Mec. Comput. 2007, 26, 2479-2495.

118. Newmark, N.M. A method of computation for structural dynamics. ASCE J. Eng. Mech. Div. 1959, 85, 67-94.

119. Rodrigues, M.V.; Correa, F.N.; Jacob, B.P. Implicit domain decomposition methods for coupled analysis of offshore platforms. Commun. Numer. Methods Eng. 2007, 23, 599-621.

120. Hearn, G.; Thomas, D.; The influence of practical time integration schemes on dynamic mooring line analysis. In Proceedings of the Offshore Technology Conference, Houston, TX, USA, 6-9 May 1991. 
121. Gobat, J.; Grosenbaugh, M. Application of the generalized- $\alpha$ method to the time integration of the cable dynamics equations. Comput. Methods Appl. Mech. Eng. 2001, 190, 4817-4829.

122. Koh, C.; Zhang, Y.; Quek, S. Low-tension cable dynamics: Numerical and experimental studies. J. Eng. Mech. $1999,125,347-354$.

123. Fitzgerald, J.; Bergdahl, L. Including moorings in the assessment of a generic offshore wave energy converter: A frequency domain approach. Mar. Struct. 2008, 21, 23-46.

124. Spanos, P.; Richichi, A.; Arena, F. Efficient Dynamic Analysis of Floating Bodies Nonlinear Behavior in Wave Energy Conversion. In Proceedings of the ASME 2013 32nd International Conference on Ocean, Offshore and Arctic Engineering, Nantes, France, 9-14 June 2013; p. V02BT02A041.

125. Spanos, P.; Richichi, A.; Arena, F. Stochastic Analysis of a Nonlinear Energy Harvester Model. In Proceedings of the ASME 2014 33rd International Conference on Ocean, Offshore and Arctic Engineering, San Francisco, CA, USA, 8-13 June 2014; p. V04BT02A036.

126. Bachynski, E.E.; Young, Y.L.; Yeung, R.W. Performance of a tethered point wave-energy absorber in regular and irregular waves. In Proceedings of the ASME 2010 3rd Joint US-European Fluids Engineering Summer Meeting Collocated with 8th International Conference on Nanochannels, Microchannels, and Minichannels, Montreal, QC, Canada, 1-5 August 2010; pp. 1133-1142.

127. Bachynski, E.E.; Young, Y.L.; Yeung, R.W. Analysis and dynamic scaling of tethered wave energy converters in irregular waves. In Proceedings of the ASME 2011 30th International Conference on Ocean, Offshore and Arctic Engineering, Rotterdam, The Netherlands, 19-24 June 2011; pp. 563-572.

128. Zaroudi, H.; Rezanejad, K.; Soares, C.G. Assessment of mooring configurations on the performance of a floating oscillating water column energy convertor. In Proceedings of the 1st International Conference of Renewable Energies Offshore, Lisbon, Portugal, 24-26 November 2014.

129. Vicente, P.C.; Antonio, F.D.O.; Gato, L.M.; Justino, P.A. Hydrodynamics of multiple floating point-absorber wave energy systems with inter-body and bottom slack-mooring connections. In Proceedings of the ASME 2009 28th International Conference on Ocean, Offshore and Arctic Engineering, Honolulu, HI, USA, 31 May-5 June 2009; pp. 1217-1227.

130. Low, Y.M.; Langley, R.S. Understanding the dynamic coupling effects in deep water floating structures using a simplified model. J. Offshore Mech. Arctic Eng. 2008, 130, 031007.

131. Sarkar, A.; Taylor, R.E. Effects of mooring line drag damping on response statistics of vessels excited by first-and second-order wave forces. Ocean Eng. 2000, 27, 667-686.

132. Sarkar, A.; Taylor, R.E. Dynamics of mooring cables in random seas. J. Fluids Struct. 2002, 16, $193-212$.

133. Grosenbaugh, M.A. On the dynamics of oceanographic surface moorings. Ocean Eng. 1996, 23, 7-25.

134. Liu, Y. Dynamics and Extreme Value Problems for Moored Floating Platforms. Ph.D. Thesis, Chalmers University of Technology, Gothenburg, Sweden, 1998.

135. Liu, Y.; Bergdahl, L. Frequency-domain dynamic analysis of cables. Eng. Struct. 1997, 19, 499-506.

136. Low, Y. Prediction of extreme responses of floating structures using a hybrid time/frequency domain coupled analysis approach. Ocean Eng. 2008, 35, 1416-1428.

137. Low, Y. Extending a time/frequency domain hybrid method for riser fatigue analysis. Appl. Ocean Res. 2011, 33, 79-87.

138. Low, Y.; Langley, R. A hybrid time/frequency domain approach for efficient coupled analysis of vessel/ mooring/riser dynamics. Ocean Eng. 2008, 35, 433-446.

139. Chatjigeorgiou, I.K.; Mavrakos, S.A. The 3D nonlinear dynamics of catenary slender structures for marine applications. In Nonlinear Dynamics; INTECH Open Access Publisher: Vukovar, Croatia, 2010; pp. 173-198.

140. Gottlieb, O.; Yim, S.C. Nonlinear oscillations, bifurcations and chaos in a multi-point mooring system with a geometric nonlinearity. Appl. Ocean Res. 1992, 14, 241-257.

141. Gottlieb, O.; Yim, S. Drag-induced instabilities and chaos in mooring systems. Ocean Eng. 1993, 20, 569-599.

142. Lin, H.; Yim, S. Noisy nonlinear motions of moored system. Part I: Analysis and simulations. J. Waterway Port Coast. Ocean Eng. 1997, 123, 287-295.

143. Kim, B.K.; Bernitsas, M.M. Nonlinear dynamics and stability of spread mooring with riser. Appl. Ocean Res. 2001, 23, 111-123.

144. Umar, A.; Datta, T.; Ahmad, S. Complex dynamics of slack mooring system under wave and wind excitations. Open Oceanogr. J. 2010, 4, 9-31. 
145. Ringwood, J.V.; Davidson, J.; Giorgi, S. Identifying models using recorded data. In Numerical Modelling of Wave Energy Converters: State-of-the-Art Techniques for Single Devices and Arrays; Elsevier: London, UK, 2016; pp. 123-147.

146. Pascoal, R.; Huang, S.; Barltrop, N.; Soares, C.G. Equivalent force model for the effect of mooring systems on the horizontal motions. Appl. Ocean Res. 2005, 27, 165-172.

147. Pascoal, R.; Huang, S.; Barltrop, N.; Soares, C.G. Assessment of the effect of mooring systems on the horizontal motions with an equivalent force to model. Ocean Eng. 2006, 33, 1644-1668.

148. Umar, A.; Datta, T. Nonlinear response of a moored buoy. Ocean Eng. 2003, 30, 1625-1646.

149. Murphy, S.; Bhinder, M.A.; Casaubieilh, P.; Sheng, W. Effects of tidal range on mooring systems of wave energy converters. In Proceedings of the 11th European Wave and Tidal Energy Conference, Nantes, France, 6-11 September 2015.

150. Kim, Y. Finite memory quadratic Volterra model for the response prediction of a slender marine structure under a Morison load. J. Fluids Struct. 2015, 56, 75-88.

151. Kim, Y. Prediction of the dynamic response of a slender marine structure under an irregular ocean wave using the NARX-based quadratic Volterra series. Appl. Ocean Res. 2015, 49, 42-56.

152. Guarize, R.; Matos, N.; Sagrilo, L.; Lima, E. Neural networks in the dynamic response analysis of slender marine structures. Appl. Ocean Res. 2007, 29, 191-198.

153. Christiansen, N.H.; Voie, P.E.T.; Høgsberg, J.; Sødahl, N. Efficient mooring line fatigue analysis using a hybrid method time domain simulation scheme. In Proceedings of the ASME 2013 32nd International Conference on Ocean, Offshore and Arctic Engineering, Nantes, France, 9-14 June 2013; p. V001T01A035.

154. De Pina, A.C.; de Pina, A.A.; Albrecht, C.H.; de Lima, B.S.L.P.; Jacob, B.P. ANN-based surrogate models for the analysis of mooring lines and risers. Appl. Ocean Res. 2013, 41, 76-86.

155. De Pina, A.C.; da Fonseca Monteiro, B.; Albrecht, C.H.; de Lima, B.S.L.P.; Jacob, B.P. ANN and wavelet network meta-models for the coupled analysis of floating production systems. Appl. Ocean Res. 2014, 48, 21-32.

156. De Pina, A.C.; Albrecht, C.H.; de Lima, B.S.L.P.; Jacob, B.P. Wavelet network meta-models for the analysis of slender offshore structures. Eng. Struct. 2014, 68, 71-84.

157. De Pina, A.A.; da Fonseca Monteiro, B.; Albrecht, C.H.; de Lima, B.S.L.P.; Jacob, B.P. Artificial Neural Networks for the analysis of spread-mooring configurations for floating production systems. Appl. Ocean Res. 2016, 59, 254-264.

158. Narayanan, S.; Yim, S.; Polo, P. Nonlinear system identification of a moored structural system. In Proceedings of the 8th International Offshore and Polar Engineering Conference, Montreal, QC, Canada, 24-29 May 1998.

159. Narayanan, S.; Yim, S. Nonlinear model evaluation via system identification of a moored structural system. In Proceedings of the 10th International Offshore and Polar Engineering Conference, Seattle, WA, USA, 28 May-2 June 2000.

160. Raman, S.; Yim, S. Parametric Identification and Sensitive Study Of a Nonlinear Moored Structure. In Proceedings of the Thirteenth International Offshore and Polar Engineering Conference, Honolulu, HI, USA, 25-30 May 2003.

161. Raman, S.; Yim, S.; Palo, P. Nonlinear model for sub-and superharmonic motions of a MDOF moored structure, part 1-System identification. J. Offshore Mech. Arctic Eng. 2005, 127, 283-290.

162. Gobat, J.I.; Grosenbaugh, M.A. A simple model for heave-induced dynamic tension in catenary moorings. Appl. Ocean Res. 2001, 23, 159-174.

163. Grosenbaugh, M.A.; Gobat, J.I.; Eck, C.F.; Modeling the dynamics of a shallow-water oceanographic surface mooring using full-scale data. Int. J. Offshore Polar Eng. 2000, 10, 10-19.

164. Gottlieb, O.; Feldman, M.; Yim, S. Parameter identification of nonlinear ocean mooring systems using the Hilbert transform. J. Offshore Mech. Arctic Eng. 1996, 118, 29-36.

165. Ormberg, H.; Larsen, K. Coupled analysis of floater motion and mooring dynamics for a turret-moored ship. Appl. Ocean Res. 1998, 20, 55-67.

166. Yang, S.H.; Ringsberg, J.W.; Johnson, E.; Hu, Z.; Palm, J. A comparison of coupled and de-coupled simulation procedures for the fatigue analysis of wave energy converter mooring lines. Ocean Eng. 2016, 117, 332-345.

167. Jacob, B.P.; de Almeida Bahiense, R.; Correa, F.N.; Jacovazzo, B.M. Parallel implementations of coupled formulations for the analysis of floating production systems, part I: Coupling formulations. Ocean Eng. 2012, 55, 206-218. 
168. Tahar, A.; Kim, M. Hull/mooring/riser coupled dynamic analysis and sensitivity study of a tanker-based FPSO. Appl. Ocean Res. 2003, 25, 367-382.

169. Idris, K. Coupled Dynamics of Bouys and Mooring Tethers. Ph.D. Thesis, Oregon State University, Corvallis, OR, USA, 1995.

170. Rhinefrank, K.; Schacher, A.; Prudell, J.; Cruz, J.; Jorge, N.; Stillinger, C.; Naviaux, D.; Brekken, T.; von Jouanne, A.; Newborn, D.; et al. Numerical and experimental analysis of a novel wave energy converter. In Proceedings of the ASME 2010 29th International Conference on Ocean, Offshore and Arctic Engineering, Shanghai, China, 6-11 June 2010; pp. 559-567.

171. DNV and Marintek. Deep C-User Manual, 4.5 Edition. 2010. Available online: https://projects.dnvgl. com/sesam/manuals/DeepC_UM.pdf (accessed on 1 January 2017).

172. MARINTEK. MIMOSA 6.3-User's Documentation. 2010. Available online: https://projects.dnvgl.com/ sesam/manuals/Mimosa_UM.pdf (accessed on 1 January 2017).

173. Det Norske Veritas (DNV). RIFLEX User's Manual; Det Norske Veritas: Høvik, Norway, 2011.

174. Parmeggiani, S.; Muliawan, M.J.; Gao, Z.; Moan, T.; Friis-Madsen, E. Comparison of mooring loads in survivability mode on the wave dragon wave energy converter obtained by a numerical model and experimental data. In Proceedings of the ASME 2012 31st International Conference on Ocean, Offshore and Arctic Engineering, Rio de Janeiro, Brazil, 1-6 July 2012; pp. 341-350.

175. Muliawan, M.J.; Gao, Z.; Moan, T. Application of the Contour Line Method for Estimating Extreme Responses in the Mooring Lines of a Two-Body Floating Wave Energy Converter. J. Offshore Mech. Arctic Eng. 2013, $135,031301$.

176. MARINTEK. SIMA—Fact Sheet. 2014. Available online: https://www.sintef.no/globalassets/upload/ marintek/software/sima.pdf (accessed on 1 January 2017).

177. MARINTEK. SIMO-User's Manual Version 3.6. 2007. Available online: https://projects.dnvgl.com/ sesam/manuals/Simo36/Simo-User_Manual.pdf (accessed on 1 January 2017).

178. Muliawan, M.J.; Karimirad, M.; Gao, Z.; Moan, T. Extreme responses of a combined spar-type floating wind turbine and floating wave energy converter (STC) system with survival modes. Ocean Eng. 2013, 65, 71-82.

179. Ren, N.; Gao, Z.; Moan, T. Long-Term Stochastic Dynamic Analysis of a Combined Floating Spar-Type Wind Turbine and Wave Energy Converter (STC) System for Mooring Fatigue Damage and Power Prediction. In Proceedings of the ASME 2014 33rd International Conference on Ocean, Offshore and Arctic Engineering, San Francisco, CA, USA, 8-13 June 2014; p. V09AT09A026.

180. MCS Kenny. Flexcom-Program Documentation. 2016. Available online: http://www.mcskenny.com/ support/flexcom/ (accessed on 1 January 2017).

181. Pizer, D.J.; Retzler, C.; Henderson, R.M.; Cowieson, F.L.; Shaw, M.G.; Dickens, B.; Hart, R. Pelamis WEC-Recent advances in the numerical and experimental modelling programme. In Proceedings of the 6th European Wave and Tidal Energy Conference, Glasgow, UK, 29 August-2 September 2005.

182. Wang, Z. An Evolutionary Optimisation Study on Offshore Mooring System Design. Ph.D. Thesis, University of Wollongong, Wollongong, Australia, 2012.

183. Soulard, T.; Babarit, A.; Borgarino, B.; Wyns, M.; Harismendy, M. C-HYP: A combined wave and wind energy platform with balanced contributions. In Proceedings of the 32nd International Conference on Ocean, Offshore and Arctic Engineering, Nantes, France, 9-14 June 2013.

184. Teillant, B.; Debruyne, Y.; Sarmento, A.; Gomes, R.; Gato, L.M.; Fontana, M.; Philippe, M.; Combourieu, A. Integration of breakthrough concepts into the OWC spar buoy. In Proceedings of the 2nd International Conference on Renewable Energies Offshore, Lisbon, Portugal, 24-28 October 2016.

185. Ruiz-Minguela, J.; Marón, A.; Prieto, M.; Rodríguez, R.; Ricci, P.; Fernández, D.; Taboada, M. Design and testing of the mooring system for a new offshore wave energy converter. In Proceedings of the 2 nd International Conference on Ocean Energy, Brest, France, 15-17 October 2008; pp. 1-9.

186. Elwood, D.; Schacher, A.; Rhinefrank, K.; Prudell, J.; Yim, S.; Amon, E.; Brekken, T.; von Jouanne, A. Numerical modeling and ocean testing of a direct-drive wave energy device utilizing a permanent magnet linear generator for power take-off. In Proceedings of the ASME 2009 28th International Conference on Ocean, Offshore and Arctic Engineering, Honolulu, HI, USA, 31 May-5 June 2009; pp. 817-824.

187. Elwood, D.; Yim, S.; Amon, E.; von Jouanne, A.; Brekken, T. Experimental force characterization and numerical modeling of a taut-moored dual-body wave energy conversion system. J. Offshore Mech. Arctic Eng. 2010, 132, 011102. 
188. Nicholls-Lee, R.; Walker, A.; Hindley, S.; Argall, R. Coupled Multi-Phase CFD and Transient Mooring Analysis of the Floating Wave Energy Converter OWEL. In Proceedings of the ASME 2013 32nd International Conference on Ocean, Offshore and Arctic Engineering, Nantes, France, 9-14 June 2013; p. V008T09A038.

189. Dynamic Systems Analysis Ltd. ProteusDS-Manual, 2.5.2135 Edition. 2013. Available online: http: / / downloads.dsa-ltd.ca/documentation/ProteusDS (accessed on 1 January 2017).

190. Ortiz, J.P.; Bailey, H.; Buckham, B.; Crawford, C.; Surrogate Based Design of a Mooring System for a Self-reacting Point Absorber. In Proceedings of the 25th International Offshore and Polar Engineering Conference, Kona, HI, USA, 21-26 June 2015.

191. Masciola, M. Instructional and theory Guide to the Mooring Analysis Program. NREL. Available online: https://nwtc.nrel.gov/system/files/MAP_v0.87.06a-mdm.pdf (accessed on 1 January 2017).

192. Hall, M. MoorDyn-Users Guide; Available online: http://www.matt-hall.ca/moordyn/ (accessed on 1 January 2017).

193. Swift, M.R.; Dewhurst, T.; Baldwin, K.; Wosnik, M. Design of a mooring system for an inertia tube wave energy collector. In Proceedings of the IEEE Oceans, St John's, NL, Canada, 14-19 September 2014.

194. Palm, J.; Eskilsson, C. MOODY-Users Manual; Chalmers Univeristy of Technology: Gothenburg, Sweden, 2014.

195. Ferri, F.; Palm, J. Implementation of a Dynamic Mooring Solver (MOODY) into a Wave to Wire Model of a Simple WEC; Technical Report; Department of Civil Engineering, Aalborg University: Aalborg, Denmark, 2015.

196. Bergdahl, L. MODEX Version 3 User's Manual; Chalmers Univeristy of Technology: Gothenburg, Sweden, 1996.

197. Gobat, J.; Grosenbaugh, M. WHOI Cable v2.0: Time Domain Numerical Simulation of Moored and Towed Oceanographic Systems; Technical Report; Woods Hole Oceanographic Institute: Woods Hole, MA, USA, 2000.

198. Chrolenko, M.O. Dynamic Analysis and Design of Mooring Lines. Master's Thesis, NTNU, Trondheim, Norway, 2013.

199. Development of a Dynamic Mooring Module FEAM for FAST v8. Technical Report. Texas A\&M University: 2014. Available online: https://nwtc.nrel.gov/system/files/2014-12-FEAM_Final_report.pdf (accessed on 1 January 2017).

200. Tjavaras, A.A. Dynamics of Highly Extensible Cables. Ph.D. Thesis, Massachusetts Institute of Technology, Cambridge, MA, USA, 1996.

201. Martinelli, L.; Spiandorello, A.; Lamberti, A.; Ruol, P. Dynamic model for catenary mooring: Experimental validation of the wave induced load. In Proceedings of the Comsol Conference, Boston, MA, USA, 7-9 October 2010.

202. Fonseca, N.; Pascoal, R.; Morais, T.; Dias, R. Design of a mooring system with synthetic ropes for the FLOW wave energy converter. In Proceedings of the ASME 2009 28th International Conference on Ocean, Offshore and Arctic Engineering, Honolulu, HI, USA, 31 May-5 June 2009; pp. 1189-1198.

203. Monarcha, A.; Fonseca, N. A static analytical method for the preliminary design of multiple line mooring systems. In Maritime Engineering and Technology; Taylor and Francis Group: London, UK, 2012.

204. Vicente, P.C.; Falcão, A.F.; Justino, P.A. Optimization of mooring configuration parameters of floating wave energy converters. In Proceedings of the ASME 2011 30th International Conference on Ocean, Offshore and Arctic Engineering, Rotterdam, The Netherlands, 19-24 June 2011; pp. 759-765.

205. Thomsen, J.B.; Ferri, F.; Kofoed, J.P. Experimental testing of mooring lines for large floating wave energy converters. In Proceedings of the 2nd International Conference on Renewable Energies Offshore, Lisbon, Portugal, 24-28 October 2016.

206. Vicente, P.C.; Falcão, A.; Justino, P. Slack-chain mooring configuration analysis of a floating wave energy converter. In Proceedings of the 26th International Workshop on Water Waves and Floating Bodies, Athens, Greece, 17-20 April 2011.

207. Saidee, M.H. Fatigue Analysis and Design of Mooring Systems. Assessment and Comparison of Different Methods. Master's Thesis, NTNU, Trondheim, Norway, 2015.

208. Low, Y.M.; Cheung, S.H. On the long-term fatigue assessment of mooring and riser systems. Ocean Eng. 2012, 53, 60-71.

209. Thies, P.R.; Johanning, L.; Smith, G.H. Lifecycle fatigue load spectrum estimation for mooring lines of a floating marine energy converter. In Proceedings of the ASME 2012 31st International Conference on Ocean, Offshore and Arctic Engineering, Rio de Janeiro, Brazil, 1-6 July 2012; pp. 667-676. 
210. Thies, P.R.; Johanning, L.; Harnois, V.; Smith, H.C.; Parish, D.N. Mooring line fatigue damage evaluation for floating marine energy converters: Field measurements and prediction. Renew. Energy 2014, 63, 133-144.

211. Yang, S.H. Analysis of Fatigue Characteristics in Mooring Lines and Low Voltage Cables for Wave Energy Converters. Licentiate Thesis, Chalmers Universtity of Technology, Gothenburg, Sweden, 2016.

212. Savin, A.; Svensson, O.; Leijon, M. Azimuth-inclination angles and snatch load on a tight mooring system. Ocean Eng. 2012, 40, 40-49.

213. Harnois, V.; Thies, P.R.; Johanning, L. On Peak Mooring Loads and the Influence of Environmental Conditions for Marine Energy Converters. J. Mar. Sci. Eng. 2016, 4, 29.

214. Parmeggiani, S.; Kofoed, J.P.; Friis-Madsen, E. Extreme loads on the mooring lines and survivability mode for the wave dragon wave energy converter. In Proceedings of the World Renewable Energy Congress, Linkoping, Sweden, 8-13 May 2011; pp. 2159-2166.

215. Liu, Y.; Bergdahl, L. Extreme mooring cable tensions due to wave-frequency excitations. Appl. Ocean Res. 1998, 20, 237-249.

216. Liu, Y.; Bergdahl, L. On combination formulae for the extremes of wave-frequency and low-frequency responses. Appl. Ocean Res. 1999, 21, 41-46.

217. Muliawan, M.J.; Gao, Z.; Moan, T.; Babarit, A. Analysis of a two-body floating wave energy converter with particular focus on the effects of power take-off and mooring systems on energy capture. J. Offshore Mech. Arctic Eng. 2013, 135, 031902.

218. Pecher, A.; Foglia, A.; Kofoed, J.P. Comparison and sensitivity investigations of a CALM and SALM type mooring system for wave energy converters. J. Mar. Scie. Eng. 2014, 2, 93-122.

219. McCabe, A.; Bradshaw, A.; Meadowcroft, J.; Aggidis, G. Developments in the design of the PS Frog Mk 5 wave energy converter. Renew. Energy 2006, 31, 141-151.

220. Vicente, P.C.; Falcão, A.D.O.; Justino, P.A. Non-linear slack-mooring modelling of a floating two-body wave energy converter. In Proceedings of the 9th European Wave and Tidal Energy Conference, Southhampton, UK, 5-9 September 2011.

221. Chen, D.; Nagata, S.; Imai, Y. Modelling wave-induced motions of a floating WEC with mooring lines using the SPH method. In Proceedings of the of the 3rd Asian Wave and Tidal Energy Conference, Singapore, 24-28 October 2016.

222. Meicke, S.A. Hydroelastic Modeling of a Wave Energy Converter Using the Arbitrary Lagrangian-Eulerian Finite Element Method in LS-DYNA. Master's Thesis, Oregon State University, Corvallis, OR, USA, 2011.

223. Yu, Y.H.; Li, Y.; Hallett, K.; Hotimsky, C. Design and analysis for a floating oscillating surge wave energy converter. In Proceedings of the ASME 2014 33rd International Conference on Ocean, Offshore and Arctic Engineering, San Francisco, CA, USA, 8-13 June 2014; p. V09BT09A048.

224. Bailey, H.; Ortiz, J.P.; Robertson, B.; Buckham, B.J.; Nicoll, R.S.; A methodology for wave-to-wire wec simulations. In Proceedings of the 2nd Marine Energy Technology Symposium, Seattle, WA, USA, 15-17 April 2014.

225. Combourieu, A.; Lawson, M.; Babarit, A.; Ruehl, K.; Roy, A.; Costello, R.; Laporte-Weywada, P.; Bailey, H. WEC3: Wave energy converters modelling code comparison project. In Proceedings of the 11th European Wave and Tidal Energy Conference, Nantes, France, 6-11 September 2015.

226. Padeletti, D.; Costello, R.; Ringwood, J.V. A Multi-Body Algorithm for Wave Energy Converters Employing Nonlinear Joint Representation. In Proceedings of the ASME 2014 33rd International Conference on Ocean, Offshore and Arctic Engineering, San Francisco, CA, USA, 8-13 June 2014; p. V09AT09A052.

227. Costello, R.; Davidson, J.; Padeletti, D.; Ringwood, J.V. Comparison of numerical simulations with experimental measurements for the response of a modified submerged horizontal cylinder moored in waves. In Proceedings of the ASME 2014 33rd International Conference on Ocean, Offshore and Arctic Engineering, San Francisco, CA, USA, 8-13 June 2014; p. V09BT09A038.

228. Ferri, F.; Ambühl, S.; Fischer, B.; Kofoed, J.P. Balancing power output and structural fatigue of wave energy converters by means of control strategies. Energies 2014, 7, 2246-2273.

229. Tom, N.M.; Yu, Y.H.; Wright, A.D.; Lawson, M. Balancing Power Absorption and Fatigue Loads in Irregular Waves for an Oscillating Surge Wave Energy Converter: Preprint. In Proceedings of the AMSE 2016 35th International Conference on Ocean. Offshore and Arctic Engineering, Busan, Korea, 19-24 June 2016.

230. Richter, M.; Magaña, M.E.; Sawodny, O.; Brekken, T.K. Power optimisation of a point absorber wave energy converter by means of linear model predictive control. IET Renew. Power Gener. 2014, 8, 203-215. 
231. Kassem, A.M.; Besheer, A.H.; Atawi, I.E. Kalmen estimator as a robust solution for output power maximization of wave energy converter. IEEJ Trans. Electr. Electron. Eng. 2015, 10, 390-395.

232. Richter, M.; Magana, M.E.; Sawodny, O.; Brekken, T.K. Nonlinear model predictive control of a point absorber wave energy converter. IEEE Trans. Sustain. Energy 2013, 4, 118-126.

233. Amann, K.U.; Magaña, M.E.; Sawodny, O. Model Predictive Control of a Nonlinear 2-Body Point Absorber Wave Energy Converter With Estimated State Feedback. IEEE Trans. Sustain. Energy 2015, 6, 336-345.

234. Ling, B. Real Time Estimation and Prediction of Wave Excitation Forces For Wave Energy Control Applications. Master's Thesis, Oregan State University, Corvallis, OR, USA, 2015.

235. Ricci, P.; Rico, A.; Ruiz-Minguela, P.; Boscolo, F.; Villate, J. Design, modelling and analysis of an integrated mooring system for wave energy arrays. In Proceedings of the 4 th International Conference on Ocean Energy, Dublin, Ireland, 17-19 October 2012.

236. Vicente, P.C.; António, F.d.O.; Gato, L.M.; Justino, P.A. Dynamics of arrays of floating point-absorber wave energy converters with inter-body and bottom slack-mooring connections. Appl. Ocean Res. 2009, 31, 267-281.

237. Vicente, P.C.; Falcão, A.D.O.; Justino, P.A. A time domain analysis of arrays of floating point-absorber wave energy converters including the effect of nonlinear mooring forces. In Proceedings of the 3rd International Conference on Ocean Energy, Bilbao, Spain, 6-8 October 2010.

238. Bailey, H.; Robertson, B.; Ortiz, J.; Buckham, B. Stochastic Methods to Predict WEC Array Power for Grid Integration. In Proceedings of the 11th European Wave and Tidal Energy Conference, Nantes, Frances, 6-11 September 2015.

239. Konispoliatis, D.N.; Mavrakos, S.A. Hydrodynamics and power absorption characteristics of free floating and moored arrays of OWC's devices. In Proceedings of the ASME 2014 33rd International Conference on Ocean, Offshore and Arctic Engineering, San Francisco, CA, USA, 8-13 June 2014; pp. 8-13.

240. Gao, Z.; Bingham, H.B.; Nicholls-Lee, R.; Adam, F.; Karmakar, D.; Karr, D.G.; Catipovic, I.; Colicchio, G.; Sheng, W.; Liu, P.; et al. Offshore Renewable Energy; Technical Report; ISSC: Cascais, Portugal, 2015.

241. Girón, A.R.C.; Corrêa, F.N.; Hernández, A.O.V.; Jacob, B.P. An integrated methodology for the design of mooring systems and risers. Mar. Struct. 2014, 39, 395-423.

242. Chen, X.; Zhang, J.; Ma, W. On dynamic coupling effects between a spar and its mooring lines. Ocean Eng. 2001, 28, 863-887.

243. Palm, J.; Eskilsson, C.; Moura Paredes, G.; Bergdahl, L. CFD simulation of a moored floating wave energy converter. In Proceedings of the 10th European Wave and Tidal Energy Conference, Aalborg, Denmark, 2-5 September 2013.

244. Jacob, B.P.; Franco, L.D.; Rodrigues, M.V.; Correa, F.N.; Jacovazzo, B.M. Parallel implementations of coupled formulations for the analysis of floating production systems, Part II: Domain decomposition strategies. Ocean Eng. 2012, 55, 219-234.

245. Strand, J.P.; Sørensen, A.J.; Fossen, T.I. Design of automatic thruster assisted mooring systems for ships. Model. Identif. Control 1998, 19, 61-75.

246. Yang, S.; Ringsberg, J.W.; Johnson, E. The Influence of biofouling on power capture and the fatigue life of mooring lines and power cables used in wave energy converters. In Proceedings of the 2nd International Conference on Renewable Energies Offshore, Lisbon, Portugal, 24-28 October 2016.

(C) 2017 by the authors; licensee MDPI, Basel, Switzerland. This article is an open access article distributed under the terms and conditions of the Creative Commons Attribution (CC BY) license (http:/ / creativecommons.org/licenses/by/4.0/). 